\title{
Validation of the Antioxidant and Enzyme Inhibitory Potential of Selected Triterpenes Using In Vitro and In Silico Studies, and the Evaluation of Their ADMET Properties
}

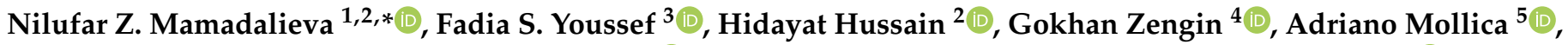 \\ Nawal M. Al Musayeib ${ }^{6}$, Mohamed L. Ashour ${ }^{3}\left({ }^{\circ}\right.$, Bernhard Westermann ${ }^{2}$ and Ludger A. Wessjohann ${ }^{2}(1)$ \\ 1 Institute of the Chemistry of Plant Substances, Academy Sciences of Uzbekistan, Tashkent 100170, Uzbekistan \\ 2 Department of Bioorganic Chemistry, Leibniz Institute of Plant Biochemistry, Weinberg 3, \\ 06120 Halle (Saale), Germany; hidayat.hussain@ipb-halle.de (H.H.); \\ bernhard.westermann@ipb-halle.de (B.W.); ludger.wessjohann@ipb-halle.de (L.A.W.) \\ 3 Department of Pharmacognosy, Faculty of Pharmacy, Ain Shams University, Cairo 11566, Egypt; \\ fadiayoussef@pharma.asu.edu.eg (F.S.Y.); ashour@pharma.asu.edu.eg (M.L.A.) \\ 4 Department of Biology, Science Faculty, Selcuk University, Konya 42130, Turkey; gokhanzengin@selcuk.edu.tr \\ 5 Department of Pharmacy, University “G. d'Annunzio" of Chieti-Pescara, 66100 Chieti, Italy; \\ a.mollica@unich.it \\ check for \\ updates \\ Citation: Mamadalieva, N.Z.; \\ 6 Department of Pharmacognosy, College of Pharmacy, King Saud University, Riyadh 11495, Saudi Arabia; \\ nalmusayeib@ksu.edu.sa \\ * Correspondence: nmamadalieva@yahoo.com
} Youssef, F.S.; Hussain, H.; Zengin, G.; Mollica, A.; Al Musayeib, N.M.; Ashour, M.L.; Westermann, B.; Wessjohann, L.A. Validation of the Antioxidant and Enzyme Inhibitory Potential of Selected Triterpenes Using In Vitro and In Silico Studies, and the Evaluation of Their ADMET Properties. Molecules 2021, 26, 6331. https: / / doi.org/

10.3390/molecules26216331

Academic Editors: Fengqing Yang, Jianbo Wan and Liya Ge

Received: 25 September 2021

Accepted: 13 October 2021

Published: 20 October 2021

Publisher's Note: MDPI stays neutral with regard to jurisdictional claims in published maps and institutional affiliations.

Copyright: (c) 2021 by the authors. Licensee MDPI, Basel, Switzerland. This article is an open access article distributed under the terms and conditions of the Creative Commons Attribution (CC BY) license (https:// creativecommons.org/licenses/by/ $4.0 /)$.

\begin{abstract}
The antioxidant and enzyme inhibitory potential of fifteen cycloartane-type triterpenes' potentials were investigated using different assays. In the phosphomolybdenum method, cycloalpioside D (6) (4.05 mmol TEs/g) showed the highest activity. In 1,1-diphenyl-2-picrylhydrazyl (DPPH*) radical and 2,2' -azino-bis(3-ethylbenzothiazoline)-6-sulfonic acid (ABTS) cation radical scavenging assays, cycloorbicoside A-7-monoacetate (2) (5.03 mg TE/g) and cycloorbicoside B (10) (10.60 mg TE/g) displayed the highest activities, respectively. Oleanolic acid (14) (51.45 mg TE/g) and 3-O- $\beta$ D-xylopyranoside-(23R,24S)-16 $\beta, 23 ; 16 \alpha, 24$-diepoxycycloart-25(26)-en-3 $\beta, 7 \beta$-diol 7-monoacetate (4) (13.25 mg TE/g) revealed the highest reducing power in cupric ion-reducing activity (CUPRAC) and ferric-reducing antioxidant power (FRAP) assays, respectively. In metal-chelating activity on ferrous ions, compound 2 displayed the highest activity estimated by $41.00 \mathrm{mg}$ EDTAE/g (EDTA equivalents $/ \mathrm{g})$. The tested triterpenes showed promising AChE and BChE inhibitory potential with 3-O- $\beta$-Dxylopyranoside-(23R,24S)-16 $\beta, 23 ; 16 \alpha, 24$-diepoxycycloart-25(26)-en-3 $\beta, 7 \beta$-diol $2^{\prime}, 3^{\prime}, 4^{\prime}, 7$-tetraacetate (3), exhibiting the highest inhibitory activity as estimated from 5.64 and $5.19 \mathrm{mg}$ GALAE/g (galantamine equivalent/g), respectively. Compound 2 displayed the most potent tyrosinase inhibitory activity (113.24 mg KAE/g (mg kojic acid equivalent/g)). Regarding $\alpha$-amylase and $\alpha$-glucosidase inhibition, 3-O- $\beta$-D-xylopyranoside-(23R,24S)-16 $\beta, 23 ; 16 \alpha, 24$-diepoxycycloart-25(26)-en-3 $\beta, 7 \beta$-diol (5) $(0.55 \mathrm{mmol} \mathrm{ACAE} / \mathrm{g}$ ) and compound 3 (25.18 mmol ACAE/g) exerted the highest activities, respectively. In silico studies focused on compounds $\mathbf{2 , 6}$, and 7 as inhibitors of tyrosinase revealed that compound 2 displayed a good ranking score $(-7.069 \mathrm{kcal} / \mathrm{mole})$ and also that the $\Delta \mathrm{G}$ freebinding energy was the highest among the three selected compounds. From the ADMET/TOPKAT prediction, it can be concluded that compounds $\mathbf{4}$ and $\mathbf{5}$ displayed the best pharmacokinetic and pharmacodynamic behavior, with considerable activity in most of the examined assays.
\end{abstract}

Keywords: antioxidants; enzyme inhibition; in vitro assays; triterpenes; virtual screening; inflammation; Alzheimer's disease

\section{Introduction}

Free radicals are highly active components that are generated naturally within the human body. They may cause many adverse effects manifested by the oxidation of lipids, 
proteins, and DNA. These harmful effects are limited by the presence of the antioxidant system that effectively protects the living organism. This protective system includes antioxidant enzymes represented by peroxidase, catalase, superoxide dismutase, glutathione, and thioredoxin. In addition, non-enzymatic antioxidants are comprised of retinol (vitamin A), ascorbic acid (vitamin C), tocopherol (vitamin E), uric acid, and glutathione. The disturbance in the balance between the antioxidant defense and the generation of free radicals causes oxidative stress [1].

This oxidative stress that mainly results from the overproduction of reactive oxygen species (ROS) triggers many hazardous disorders including cancer, cardiovascular diseases, atherosclerosis, obesity, diabetes, and inflammatory diseases [2,3]. Diabetes mellitus is a serious metabolic disease characterized by hyperglycemia, polydipsia, polyphagia, and frequent urination that attacks nearly $10 \%$ of the population worldwide [4]. Moreover, Alzheimer's disease (AD) is an irreversible neurological disorder that occurs progressively and its incidence is consequently elevated with age [5].

Meanwhile, naturally occurring antioxidants counteract oxidative stress to a great extent, showing a wide range of biological activities. They effectively prohibited oxidative stress-associated disorders including neurodegenerative disorders and diabetes as well [6-9]. Hence, phytoconstituents derived from different organisms, but mostly from plants, have become the focus of many types of antioxidant and anti-inflammatory research studies for nutraceutical and drug discovery, e.g., as lead entities adopted by pharmaceutical companies. The plant kingdom constitutes a hub for highly popular natural antioxidants, represented mainly by ascorbate and polyphenolic compounds such as flavonoids, tocopherols, and phenolic terpenoids. Furthermore, these phytochemicals afford many other activities that can relieve many diseases in addition to their pronounced antioxidant potential [10-12].

Terpenes represent a large category of naturally occurring compounds possessing significant biological activities. Many polycyclic triterpenes, especially sterols, are biosynthesized via squalene epoxide arrangements in a chair-chair-chair-boat manner that is consequently followed by condensation. Terpenes include several classes represented by mono and sesquiterpene components that prevail in essential oils, diterpenes, and triterpenes (with steroids) of different types, as well as in tetraterpene carotenoids and polyterpenes. Nowadays, there is an increasing interest in natural triterpenoids due to their outstanding biological activities as exemplified by reported anticancer, antiviral, bactericidal, spermicidal, anti-allergic, fungicidal, and cardiovascular protective effects [13-17].

Triterpenes are classified into many subclasses per their chemical structure. The main groups of triterpenoids and their glycosides are represented by tetracyclic derivatives of the cycloartane, euphane, protostane, and dammarane type, in addition to the pentacyclic derivatives of the gammacerane, hopane, ursane, and lupine type. This study aimed to investigate the antioxidant and enzyme inhibitory potential of fifteen triterpenes. The antioxidant activity was determined using different assays, including total antioxidant activity by the phosphomolybdenum method; 1,1-diphenyl-2-picrylhydrazyl $\left(\mathrm{DPPH}^{*}\right) \mathrm{rad}-$ ical scavenging activity, 2,2'-azinobis(3-ethylbenzothiazoline)-6-sulfonic acid (ABTS) cation radical scavenging activity, cupric ion-reducing activity (CUPRAC), and the ferric-reducing antioxidant power (FRAP) assay; as well as metal-chelating activity on the ferrous ions assay. Furthermore, the enzyme inhibitory potential was investigated via determining the inhibitory potential of the fifteen triterpenes on acetylcholinesterase, butyrylcholinesterase, tyrosinase, $\alpha$-amylase, and $\alpha$-glucosidase enzymes. Additionally, the examined triterpenes were subjected to molecular modelling studies on tyrosinase enzymes, followed by MMGBSA (molecular mechanics energies combined with generalized Born and surface area continuum solvation) calculations of the obtained docking poses. Furthermore, the prediction of ADMET (absorption, distribution, metabolism, excretion, and toxicity) properties as well as TOPKAT (toxicity prediction) for all of the examined molecules was performed using Discovery Studio 4.5 software (Accelrys Inc., San Diego, CA, USA). 


\section{Results and Discussion}

\subsection{Triterpenes Used in This Study}

Fifteen triterpenes were used in this study and they are illustrated in Figure 1: cycloorbicoside A (1), cycloorbicoside A-7-monoacetate (2), 3-O- $\beta$-D-xylopyranoside-(23R,24S)$16 \beta, 23 ; 16 \alpha, 24$-di-epoxycycloart-25(26)-en-3 $\beta, 7 \beta$-diol2 $2^{\prime}, 3^{\prime}, 4^{\prime}, 7$-tetraacetate (3), 3-O- $\beta$-D-

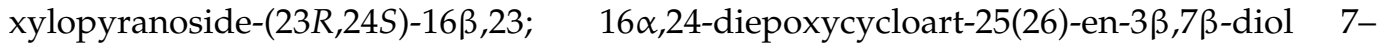
monoacetate (4), 3-O- $\beta$-D-xylopyranoside-(23R,24S)-16 $\beta, 23 ; 16 \alpha, 24$-diepoxycycloart-25(26)en-3 $\beta, 7 \beta$-diol (5), cycloalpioside D (6), cycloalpioside D-2', $3^{\prime}, 4^{\prime}, 7$-tetraacetate (7), cycloalpioside D-2', $3^{\prime}, 4^{\prime}$-triacetate (8), 3-O- $\beta$-D-xylopyronoside-20R-25-norcycloartan-3 $\beta, 7 \beta, 16 \beta$ triol-20,24-olide (9), cycloorbicoside B (10), cyclosiversioside E (11), astragaloside IV (cyclosieversioside F or astrasieversianin XIV) (12), cyclosiversioside H (13), oleanolic acid (14), and ursolic acid (15).

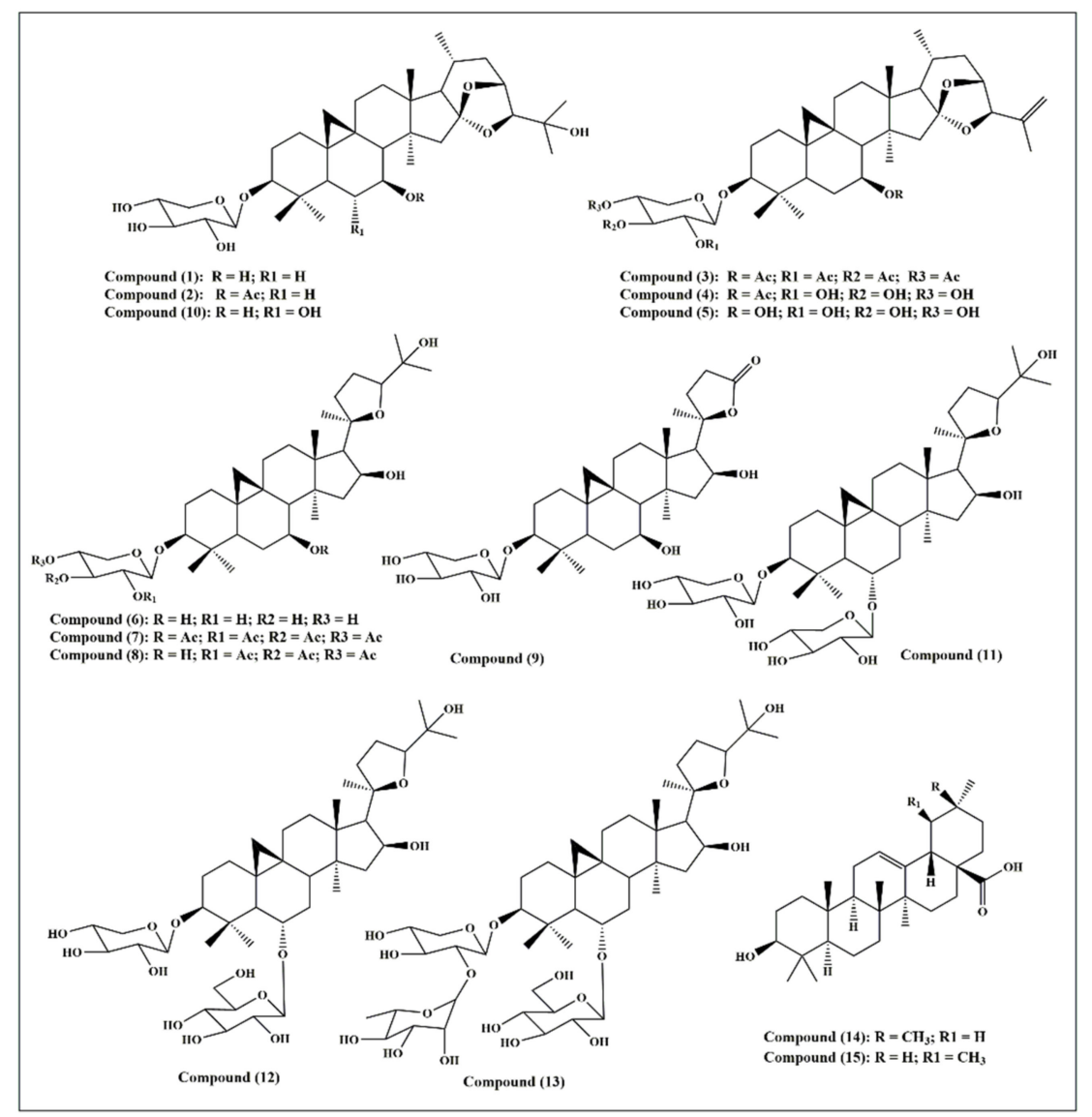

Figure 1. A scheme showing the fifteen triterpene compounds selected for this study.

2.2. In Vitro Assays for the Evaluation of the Antioxidant Activity of the Studied Triterpenes 2.2.1. Total Antioxidant Activity by the Phosphomolybdenum Method

The phosphomolybdenum method was used to evaluate the total antioxidant activity of all the compounds studied. The molybdenum ion-reducing potential of various compounds is illustrated in Table 1. Basically, $\mathrm{Mo}(\mathrm{VI})$ is reduced to $\mathrm{Mo}(\mathrm{V})$ by the action of antioxidant compounds that results in the formation of the green phosphate $/ \mathrm{Mo}(\mathrm{V}) \mathrm{com}$ plex as a byproduct, which is detected spectrophotometrically at $\lambda=695 \mathrm{~nm}$. Compound 6 (4.05 mmol TEs/g), followed by compounds 2 ( $2.26 \mathrm{mmol} \mathrm{TEs} / \mathrm{g}), 3(1.98 \mathrm{mmol} \mathrm{TEs} / \mathrm{g})$, and $11(1.90 \mathrm{mmol}$ TEs/g), showed the highest total antioxidant activity. In contrast, compound 14 revealed the lowest activity in this assay $(0.2 \mathrm{mmol}$ TEs $/ \mathrm{g}$; Table 1$)$. 
Table 1. Antioxidant activity of fifteen triterpenes, employing the phosphomolybdenum method, and metal-chelating activity on ferrous ion assays.

\begin{tabular}{|c|c|c|}
\hline Compounds & $\begin{array}{l}\text { Phosphomolybenum } \\
\text { (mmol TE/g) }\end{array}$ & $\begin{array}{l}\text { Metal-Chelating } \\
\text { (mg EDTAE/g) }\end{array}$ \\
\hline Cycloorbicoside A (1) & $1.82 \pm 0.04$ & $18.54 \pm 0.06$ \\
\hline Cycloorbicoside A-7-monoacetate (2) & $2.26 \pm 0.22$ & $41.00 \pm 0.37$ \\
\hline $\begin{array}{c}\text { 3-O- } \beta \text {-D-Xylopyranoside-(23R,24S)-16 } \beta, 23 ; 16 \alpha, 24 \text {-diepoxycycloart-25(26)-en-3 } \beta, 7 \beta \text {-diol } \\
2^{\prime}, 3^{\prime}, 4^{\prime}, 7 \text {-tetraacetate (3) }\end{array}$ & $1.98 \pm 0.06$ & $18.16 \pm 0.72$ \\
\hline 3-O- $\beta$-D-Xylopyranoside-(23R,24S)-16 $\beta, 23 ; 16 \alpha, 24$-diepoxycycloart-25(26)-en-3 $\beta, 7 \beta$-diol-7-monoacetate (4) & $1.34 \pm 0.01$ & $21.88 \pm 0.96$ \\
\hline 3-O- $\beta$-D-Xylopyranoside- $(23 R, 24 S)-16 \beta, 23 ; 16 \alpha, 24$-diepoxycycloart-25(26)-en-3 $\beta, 7 \beta$-diol (5) & $0.80 \pm 0.01$ & $15.64 \pm 0.28$ \\
\hline Cycloalpioside D (6) & $4.05 \pm 0.01$ & $19.03 \pm 0.07$ \\
\hline Cycloalpioside D-2', $3^{\prime}, 4^{\prime}, 7$-tetraacetate (7) & $1.58 \pm 0.16$ & $25.38 \pm 0.08$ \\
\hline Cycloalpioside D-2 $2^{\prime}, 3^{\prime}, 4^{\prime}$-triacetate $(8)$ & $1.78 \pm 0.02$ & $19.26 \pm 0.33$ \\
\hline 3-O- $\beta$-D-Xylopyranoside-20R-25-norcycloartan-3 $\beta, 7 \beta, 16 \beta$-triol-20,24-olide (9) & $0.45 \pm 0.02$ & $20.19 \pm 0.21$ \\
\hline Cycloorbicoside B (10) & $1.49 \pm 0.17$ & $4.68 \pm 0.08$ \\
\hline Cyclosieversioside E (11) & $1.90 \pm 0.16$ & $8.33 \pm 0.24$ \\
\hline Astragaloside IV (12) & $1.30 \pm 0.04$ & $8.73 \pm 0.04$ \\
\hline Cyclosieversioside H (13) & $0.83 \pm 0.06$ & $3.96 \pm 0.14$ \\
\hline Oleanolic acid (14) & $0.20 \pm 0.01$ & $3.05 \pm 0.14$ \\
\hline Ursolic acid (15) & $0.42 \pm 0.10$ & $30.17 \pm 0.07$ \\
\hline
\end{tabular}

Values are reported as mean \pm S.D.; TE: Trolox equivalents; and EDTAE: EDTA equivalents.

\subsubsection{1,1-Diphenyl-2-Picrylhydrazyl (DPPH*) Radical Scavenging Capacity Assay}

This assay depends on the bleaching of the purple color of the DPPH methanol solution due to the electron or hydrogen atom donating capability of the tested sample that causes a reduction in the radical solutions and is directly correlated to the antioxidant ability of the tested sample [18]. Results illustrated in Figure 2A show that cycloorbicoside A-7-monoacetate (2) (5.03 mg TE/g) showed the highest activity, followed by compounds $\mathbf{9}$ (4.80 mg TE/g), 6 (3.86 mg TE/g), and 7 (3.79 mg TE/g). In contrast, cyclosiversioside H (13) revealed the lowest activity $(0.10 \mathrm{mg} \mathrm{TE} / \mathrm{g}$; Figure $2 \mathrm{~A})$.

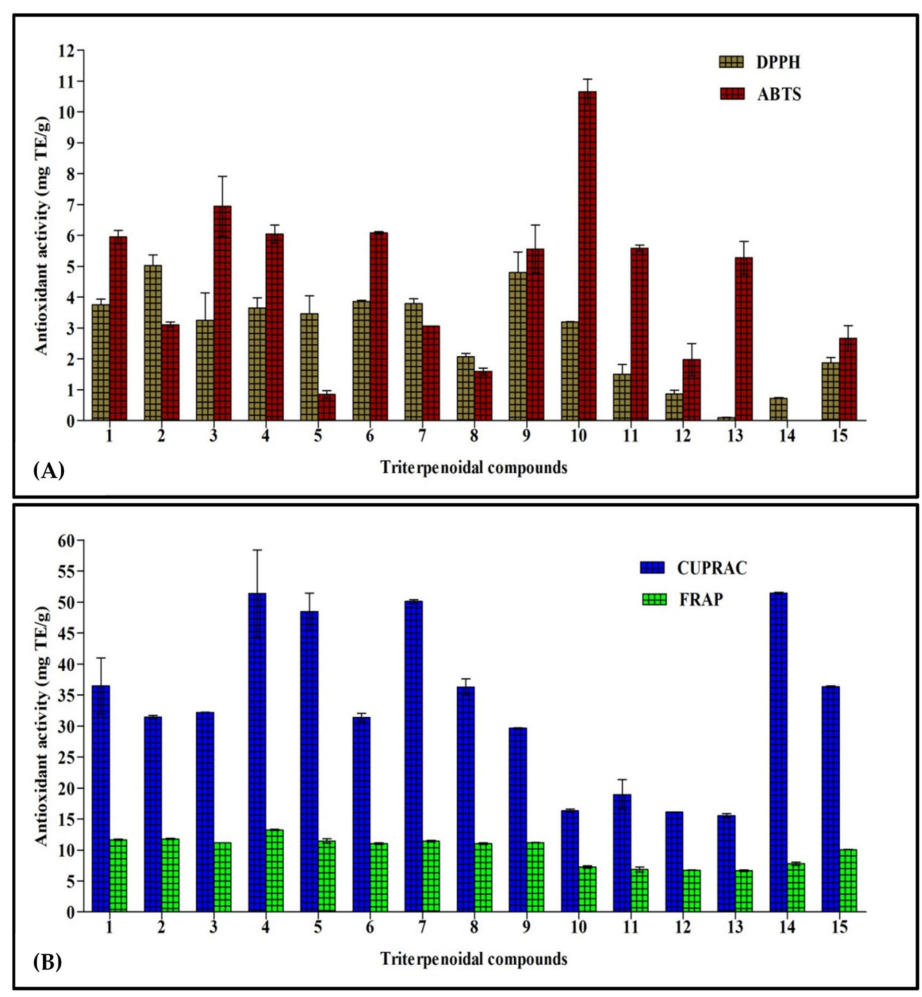

Figure 2. Antioxidant activity of fifteen triterpenes, employing DPPH and ABTS (A), and CUPRAC and FRAP (B) expressed in $\mathrm{mg}$ TE/g. Values are reported as mean \pm S.D.; TE: Trolox equivalents. 


\subsubsection{2,2'-Azinobis(3-Ethylbenzothiazoline)-6-Sulfonic Acid (ABTS) Cation Radical} Scavenging Activity

In this assay, the colored free radical 2,2'-azino-bis(3-ethylbenzthiazoline-6-sulfonic acid) radical $\left(\mathrm{ABTS}^{+}\right)$was greatly employed to evaluate the capability of a compound to transfer electrons, which is widely correlated to the presence of antioxidants in the solution. Cycloorbicoside B (10) displayed the highest activity in this assay $(10.60 \mathrm{mg} \mathrm{TE} / \mathrm{g})$, followed by the compounds $3(6.95 \mathrm{mg} \mathrm{TE} / \mathrm{g}), \mathbf{6}(6.08 \mathrm{mg} \mathrm{TE} / \mathrm{g})$, and $\mathbf{4}(6.05 \mathrm{mg} \mathrm{TE} / \mathrm{g})$. At the other end, oleanolic acid (14) revealed no activity in this assay (Figure 2A).

\subsubsection{Cupric Ion-Reducing Activity (CUPRAC) Assay}

Reducing power is frequently adopted as an indicator for donating electrons, which represents one of the most important mechanisms of antioxidants. The CUPRAC assay determines the reduction of cupric $\left(\mathrm{Cu}^{2+}\right)$-neocuproine to cuprous ion $\left(\mathrm{Cu}^{+}\right)$. In this assay, oleanolic acid (14) revealed the highest reducing power, as evidenced by the results of the CUPRAC assay with activity equaling to $51.45 \mathrm{mg}$ TE/g. This was followed by compounds 4 and 7 that displayed a reducing activity estimated at 51.4 and $50.1 \mathrm{mg} \mathrm{TE} / \mathrm{g}$, respectively, while cyclosiversioside $\mathrm{H}$ (13) revealed the lowest activity (15.5 mg TE/g; Figure 2B).

\subsubsection{Ferric-Reducing Antioxidant Power (FRAP) Assay}

FRAP is a simple, fast, and reliable method that estimates the reduction of ferric ion $\left(\mathrm{Fe}^{3+}\right)$ to ferrous $\left(\mathrm{Fe}^{2+}\right)$, which is highly correlated with the antioxidant potential of phytochemicals and is detected spectrophotometrically. Compound 4 exerted the most potent FRAP activity, showing $13.3 \mathrm{mg}$ TE/g. Meanwhile, all other compounds, namely 1-9, revealed activity in the range of 11.0-11.8 mg TE/g, followed by ursolic acid (15) that showed activity $(10.0 \mathrm{mg} \mathrm{TE} / \mathrm{g})$. The compound 13 revealed the lowest activity (6.7 mg TE/g; Figure 2B).

\subsubsection{Metal-Chelating Activity on Ferrous Ions}

Enzyme activity within the human body greatly depends on the presence of transition elements; meanwhile, they contain some unpaired electrons that combine fast with peroxides producing alkoxyl radicals. Thus, antioxidants that perfectly chelate these ions can inhibit their action, providing a reliable mechanism to combat oxidative stress. Herein, the determination of the formation of ferrous ion-ferrozine complexes was used to investigate the metal-chelating potential of the studied triterpenes. Cycloorbicoside A 7-monoacetate (2) displayed the highest metal-chelating activity on ferrous ions at $41.0 \mathrm{mg}$ EDTAE/g. This was followed by ursolic acid (15), cycloalpioside D- $2^{\prime}, 3^{\prime}, 4^{\prime}, 7$-tetraacetate (7), and 3-O- $\beta$-D-xylopyranoside-(23R,24S)-16 $\beta, 23 ; 16 \alpha, 24$-diepoxycycloart-25(26)-en-3 $\beta, 7 \beta$-diol 7monoacetate (4), displaying activities of 30.2, 25.4, and $21.9 \mathrm{mg}$ EDTAE/g, respectively. However, oleanolic acid (14) showed the lowest activity in this assay, which was equal to $3.05 \mathrm{mg}$ EDTAE/g (Table 1).

Most of the tested compounds showed good antioxidant activities in one or more assays but with different preferences. That undoubtedly reflects their different antioxidant activity modes. Some displayed their antioxidant potential through the scavenging of free radicals, as in DPPH and ABTS assays. Meanwhile, others showed a reduction of antioxidant power, as in the FRAP, CUPRAC, and phosphomolybdenum method assays, or acted by chelating the ions in biorelevant transition elements avoiding electron transfer, such as in the ferrous ion assay.

\subsection{In Vitro Assays for the Evaluation of the Enzyme Inhibitory Activity of the Studied Triterpenes}

\subsubsection{Cholinesterase (ChE) Inhibitory Activity}

Cholinesterasas form a family of enzymes that specifically cleave choline-based esters that mainly act as neurotransmitters. Acetylcholinesterase (AChE) and butyrylcholinesterase (BChE) are the two types of cholinesterase that widely differ according to the cholinergic substrate, with an acetylcholin preference for $\mathrm{AChE}$ and butyrylcholine 
for BChE. Inhibition of cholinesterases results in an elevated level of neurotransmitters and thus can serve as a promising strategy for temporarily alleviating certain neurodegenerative disorders, such as Alzheimer's disease. All triterpenes tested showed acetylcholinesterase $\mathrm{AChE}$ and $\mathrm{BChE}$ inhibitory potential, except for compound 8 that had no acetylcholinesterase inhibitory activity. 3-O- $\beta$-D-Xylopyranoside-(23R,24S)-16 $\beta, 23 ; 16 \alpha, 24$ di-epoxycycloart-25(26)-en-3 $\beta, 7 \beta$-diol $2^{\prime}, 3^{\prime}, 4^{\prime}, 7$-tetraacetate (3) exhibited the highest inhibitory activity for both AChE and BChE, with activities of 5.64 and $5.19 \mathrm{mg}$ GALAE/g, respectively. Regarding $\mathrm{AChE}$, other compounds, namely 1-9 and excluding compound 8, showed inhibitory activity ranging between 5.07 and $5.45 \mathrm{mg}$ GALAE/g, while compounds 10-15 displayed an inhibitory potential between 2.07 and $2.65 \mathrm{mg}$ GALAE/g. Concerning $\mathrm{BChE}$, most of the compounds showed a considerable inhibitory effect in the range of 4.13-5.18 mg GALAE/g, except compounds $\mathbf{1 4}$ and 15 that showed almost equal BChE inhibitory activity (2.06 and $2.20 \mathrm{mg}$ GALAE/g, respectively) (Figure 3).

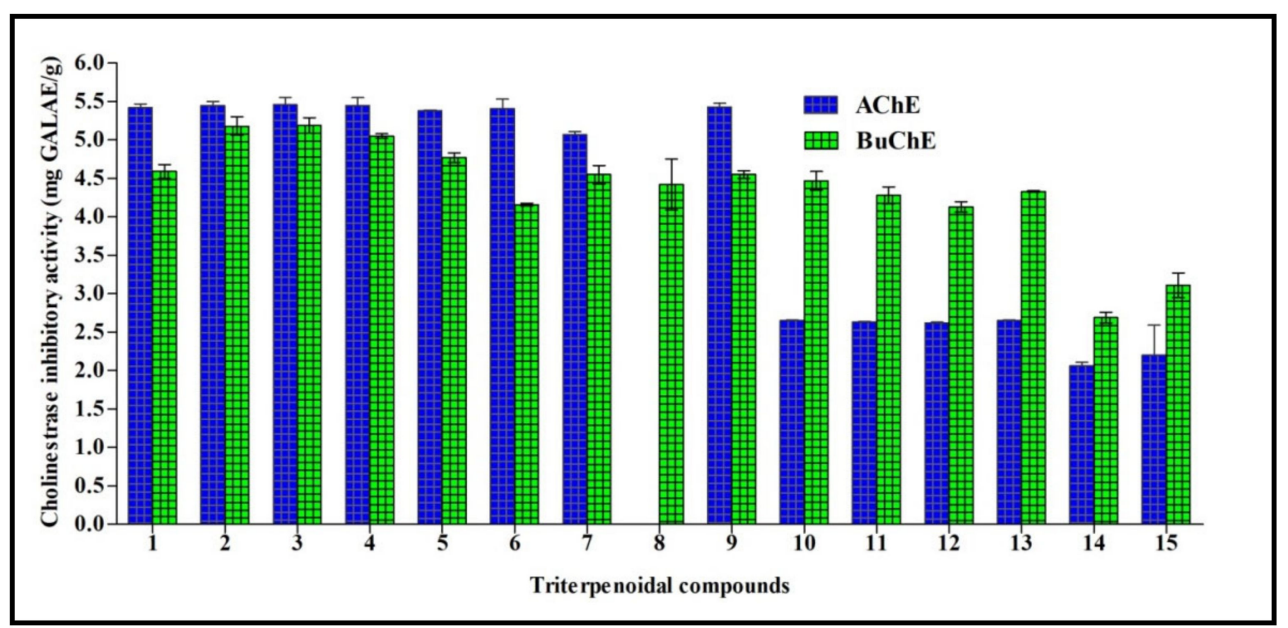

Figure 3. Cholinestrase inhibitory activity of fifteen triterpenes expressed in $\mathrm{mg}$ GALAE/g. Values are reported as mean \pm S.D.; GALAE: Galatamine equivalent.

\subsubsection{Tyrosinase Inhibitory Activity}

Tyrosinase is a polyphenol oxidase enzyme that contains copper and greatly influences the process of melanogenesis. It changes L-tyrosine into L-DOPA with consequent oxidation to dopachrome that stimulates the generation of melanin. Melanin is crucial to counteract the damage caused to hair, skin, and eyes triggered by UV. However, its overproduction is accompanied by the appearance of freckles, melisma, and neurodegenerative disorders [19]. Thus, tyrosinase inhibition elicited by natural compounds is the target of many research programs to counteract various disorders and cosmetic problems. Cycloorbicoside A7-monoacetate (2) displayed the most potent tyrosinase inhibitory activity, estimated at $113.24 \mathrm{mg} \mathrm{KAE} / \mathrm{g}$, followed by the compounds 6, 7, and 1 that showed 67.79, 64.19, and $61.24 \mathrm{mg} \mathrm{KAE} / \mathrm{g}$, respectively. However, compounds $\mathbf{1 2}$ and $\mathbf{1 4}$ revealed the lowest activity, estimated at 27.42 and $27.76 \mathrm{mg} \mathrm{KAE/g}$, respectively (Figure 4).

\subsection{3. $\alpha$-Amylase and $\alpha$-Glucosidase Inhibitory Activity}

Both $\alpha$-amylase and $\alpha$-glucosidase acted as biocatalysts to cleave glycosidic bonds $(1,4)$ in glycogen or starch. Additionally, $\alpha$-glucosidase catalyzed the last step in carbohydrate hydrolyses, resulting in the production of glucose. Regarding the inhibition of $\alpha$-amylase, 3-O- $\beta$-D-xylopyranoside-(23R,24S)-16 $\beta, 23 ; 16 \alpha, 24$-diepoxycycloart-25(26)-en$3 \beta, 7 \beta$-diol (5) exerted the highest activity $(0.55 \mathrm{mmol} \mathrm{ACAE} / \mathrm{g})$, followed by ursolic acid (15) $(0.45 \mathrm{mmol} \mathrm{ACAE} / \mathrm{g})$ and 3-O- $\beta$-D-xylopyranoside- $(23 R, 24 S)-16 \beta, 23$, and then $16 \alpha, 24-$ diepoxycycloart-25(26)-en-3 $\beta, 7 \beta$-diol-7-monoacetate (4) (0.42 mmol ACAE/g). However, 3 -O- $\beta$-D-xylopyronoside-20R-25-norcycloartan-3 $\beta, 7 \beta, 16 \beta$-triol-20,24-olide (9) revealed the lowest activity $(0.13 \mathrm{mmol} \mathrm{ACAE} / \mathrm{g})$. 


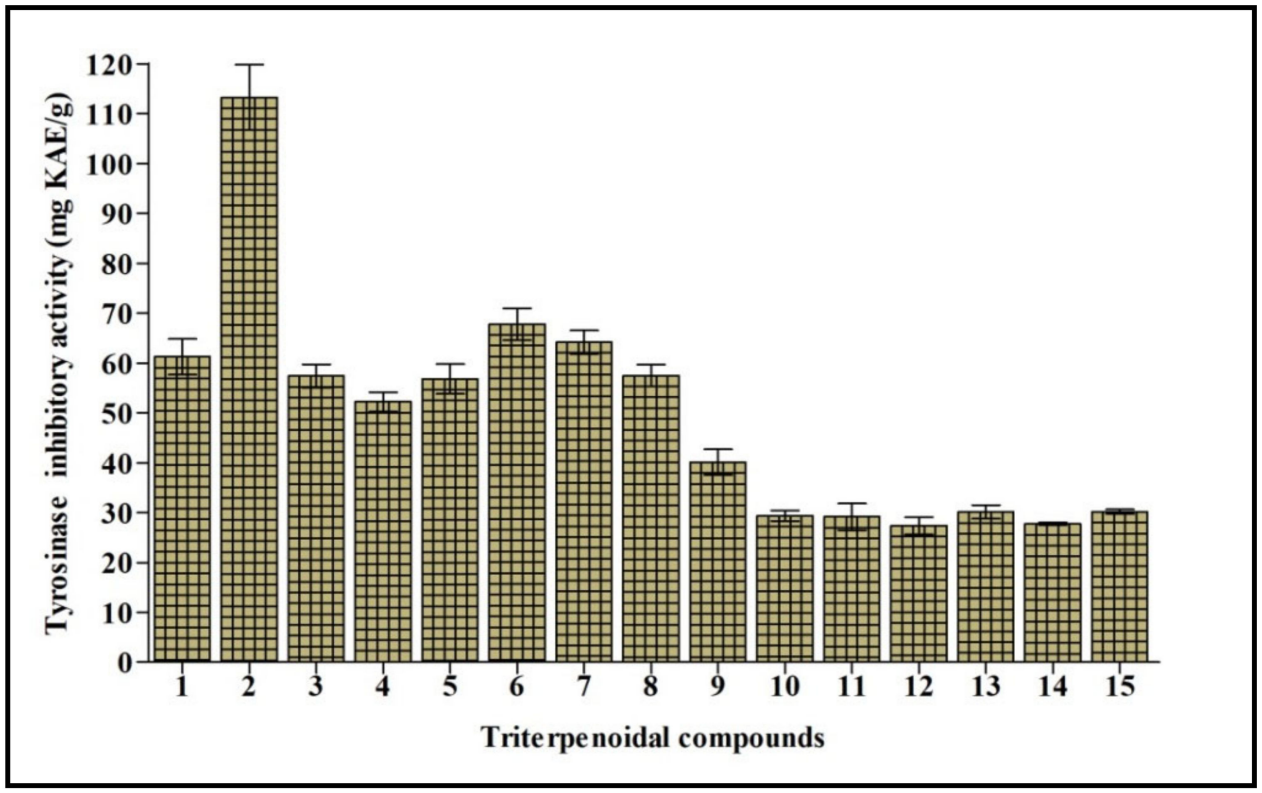

Figure 4. Tyrosinase inhibitory activity of fifteen triterpenes expressed in mg KAE/g. Values are reported as mean \pm S.D.; KAE: Kojic acid equivalent. Different letters indicate significant differences in the tested compounds $(p<0.05)$.

Concerning $\alpha$-glucosidase, $3-O-\beta$-D-xylopyranoside-(23R,24S)-16 $\beta, 23 ; 16 \alpha, 24$-diepoxycycloart-25(26)-en-3 $\beta, 7 \beta$-diol (3) showed the highest activity (25.18 mmol ACAE/g). On the contrary, cycloorbicoside A (1), cycloorbicoside A-7-monoacetate (2), 3-O- $\beta$-Dxylopyronoside-20R-25-norcycloartan-3 $\beta, 7 \beta, 16 \beta$-triol-20,24-olide (9), cycloorbicoside B (10), and cyclosiversioside $\mathrm{H}(\mathbf{1 3})$ exerted no effect on the inhibition of $\alpha$-glucosidase. Additionally, the remaining compounds displayed inhibitory potentials from 19.36 to 24.90 $\mathrm{mmol} \mathrm{ACAE} / \mathrm{g}$ (Table 2).

Table 2. $\alpha$-Amylase and $\alpha$-glucosidase inhibitory activity of fifteen triterpenes expressed in mmol ACAE/g.

\begin{tabular}{|c|c|c|}
\hline Compounds & $\alpha$-Amylase & $\alpha$-Glucosidase \\
\hline Cycloorbicoside A (1) & $0.14 \pm 0.02$ & NA \\
\hline Cycloorbicoside A-7-monoacetate (2) & $0.33 \pm 0.02$ & NA \\
\hline 3-O- $\beta$-D-Xylopyranoside-(23R,24S)-16 $\beta, 23 ; 16 \alpha, 24$-diepoxycycloart-25(26)-en-3 $\beta, 7 \beta$-diol $2^{\prime}, 3^{\prime}, 4^{\prime}, 7$-tetraacetate (3) & $0.29 \pm 0.01$ & $25.18 \pm 0.02$ \\
\hline 3-O- $\beta$-D-Xylopyranoside-(23R,24S)-16 $\beta, 23 ; 16 \alpha, 24$-diepoxycycloart-25(26)-en-3 $\beta, 7 \beta$-diol-7-monoacetate (4) & $0.42 \pm 0.06$ & $24.90 \pm 0.09$ \\
\hline 3-O- $\beta$-D-Xylopyranoside-(23R,24S)-16 $\beta, 23 ; 16 \alpha, 24$-diepoxycycloart-25(26)-en-3 $\beta, 7 \beta$-diol (5) & $0.55 \pm 0.04$ & $24.87 \pm 0.12$ \\
\hline Cycloalpioside D (6) & $0.35 \pm 0.06$ & $24.08 \pm 1.06$ \\
\hline Cycloalpioside D-2', $3^{\prime}, 4^{\prime}, 7$-tetraacetate (7) & $0.33 \pm 0.06$ & $24.73 \pm 0.04$ \\
\hline Cycloalpioside D-2' $3^{\prime}, 4^{\prime}$-triacetate $(8)$ & $0.17 \pm 0.01$ & $24.82 \pm 0.05$ \\
\hline 3-O- $\beta$-D-Xylopyranoside-20R-25-norcycloartan-3 $\beta, 7 \beta, 16 \beta$-triol-20,24-olide (9) & $0.13 \pm 0.09$ & NA \\
\hline Cycloorbicoside B (10) & $0.25 \pm 0.02$ & NA \\
\hline Cyclosieversioside E (11) & $0.27 \pm 0.01$ & NA \\
\hline Astragaloside IV (12) & $0.22 \pm 0.03$ & $19.36 \pm 0.01$ \\
\hline Cyclosieversioside H (13) & $0.29 \pm 0.01$ & NA \\
\hline Oleanolic acid (14) & $0.29 \pm 0.01$ & $20.02 \pm 0.07$ \\
\hline Ursolic acid (15) & $0.45 \pm 0.01$ & $21.42 \pm 0.01$ \\
\hline
\end{tabular}

Values are reported as mean \pm S.D.; ACAE: Acarbose equivalent; and NA: not active.

All triterpenes showed acetylcholinesterase (AChE) and butyrylcholinesterase (BChE) inhibitory potential. Additionally, some showed inhibitory activity towards tyrosinase, $\alpha$-amylase, and $\alpha$-glucosidase to different degrees. Enzyme inhibitory therapeutic strategies are the most promising and established strategies for alleviating disorders, including diabetes mellitus and Alzheimer's disease, that are dramatically increasing in modern times. Patients who have Alzheimer's disease possess low levels of acetylcholine, an important neurotransmitter of the brain. Thus, inhibition of acetylcholinesterase (AChE) that catalyzes acetylcholine hydrolysis is used to treat Alzheimer's disease to some extent. The use of enzymes that play a role in carbohydrate digestion, such as $\alpha$-amylase and 
$\alpha$-glucosidase, is among the promising strategies for natural products and related compounds to control blood glucose levels associated with diabetes mellitus $[19,20]$. Many cycloartane-type triterpenes have been reported to possess antioxidant and $\alpha$-glucosidase inhibitory activity, such as mangiferolic acid isolated from propolis collected by the Indonesian stingless bee (Tetragonula sapiens Cockerell) propolis [21]. In addition, cycloartane glycosides isolated from Astragalus plumosus var. krugianus revealed potent protective effects against oxidative stress [22]. Furthermore, one new cycloartane triterpene, namely (22Z,24E)-3ß-hydroxycycloart-14,22,24-trien-26-oic acid isolated from Garcinia hombroniana bark, displayed potent cholinesterase inhibitory potential versus both acetylcholinesterase and butyrylcholinesterase [23]. New cycloartane-type triterpenoids isolated from the Amberboa ramosa entire plant revealed considerable tyrosinase inhibitory potential, together with those isolated from Astragalus, and thus could serve as skin-whitening agents in pharmaceuticals or cosmeceuticals [24,25].

\subsection{Molecular Modelling Study}

Computational techniques have been successfully used for the prediction of the ligandtarget interaction [26,27]. For this study, we selected the enzyme tyrosinase as the molecular target, as some of the compounds tested in the in vitro assays demonstrated a high activity for the inhibition of this enzyme (Figure 5), e.g., compounds 2, 6, and 7. In particular, compound 2 showed the highest inhibition activity among the fifteen tested compounds.

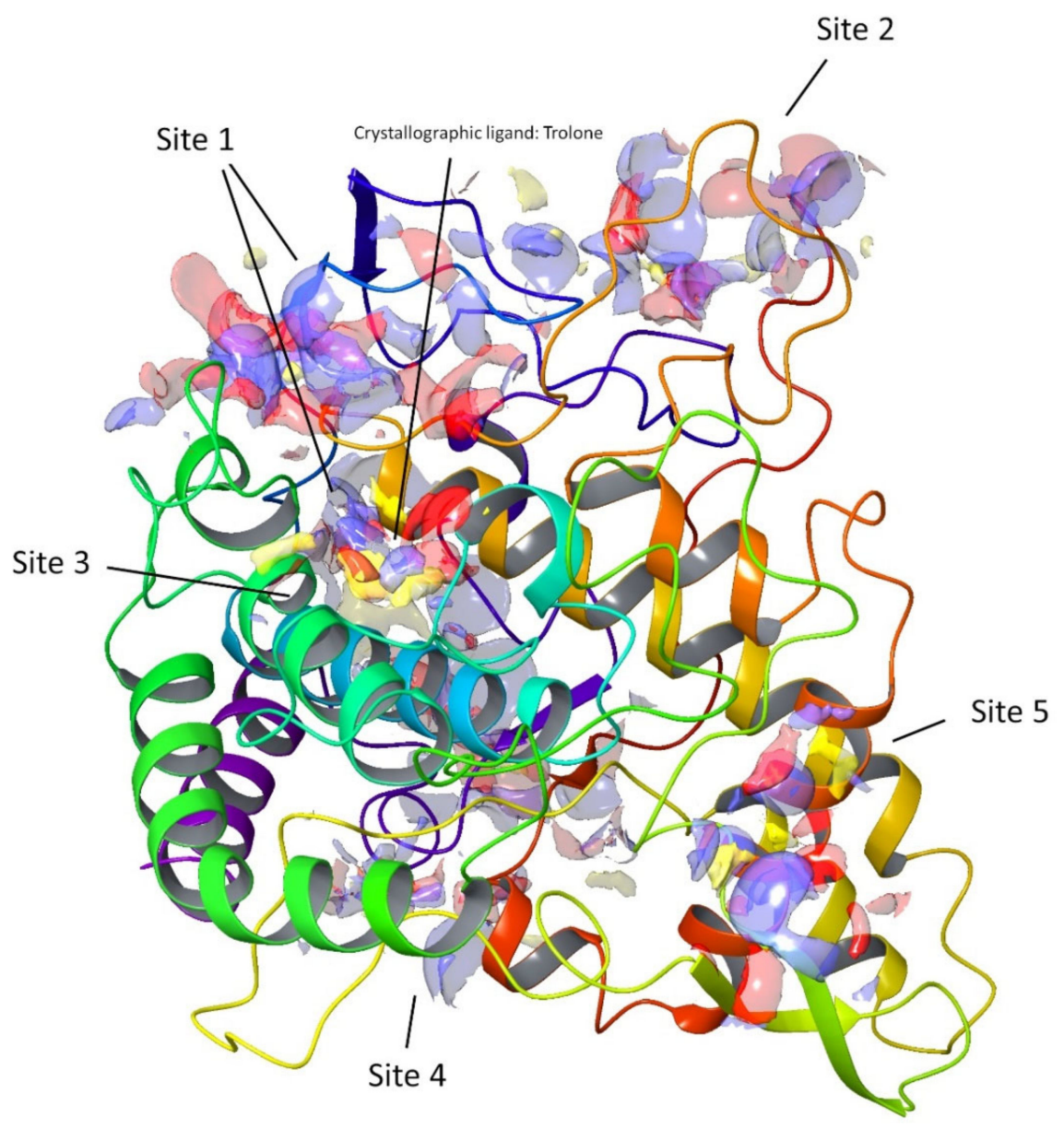

Figure 5. Top-ranked potential receptor-binding sites with hydrophobic (yellow), hydrogen-bond donor (blue), and hydrogen-bond acceptor (red) maps presented.

In the early stage of docking performed with the standard precision method, we observed that these triterpenes according to their molecular weight, which is sensibly 
higher than the natural substrates of tyrosinase, such as L-dopa and tyrosine, cannot penetrate in the depth of the enzymatic pocket. Thus, in order to better understand which could be the most plausible interaction site for this class of molecules, the enzyme was subjected to a binding site search by the Sitemap routine included in Maestro [28]. This experiment returned five top-ranked potential receptor binding sites, as depicted in Figure 5. For each of the sites a docking grid was constructed and the three selected compounds 2, 6, and 7 were docked onto them. The best docking values were obtained for site1, which is the site containing the enzymatic cavity and surrounding area on the surface of the enzyme. Thus, site1 (Figure 6) was taken as a reference binding site and all the substances were docked with the extra precision method. After the docking calculation, the compounds revealed a docking score ranking in agreement with the in vitro data, in which compound $\mathbf{2}$ was more active than the other two. Additionally, the calculation of the DG free-binding energy was calculated by the MM-GBSA method included in Maestro and the results are also in agreement with the in vitro assay (Figure 4).

A

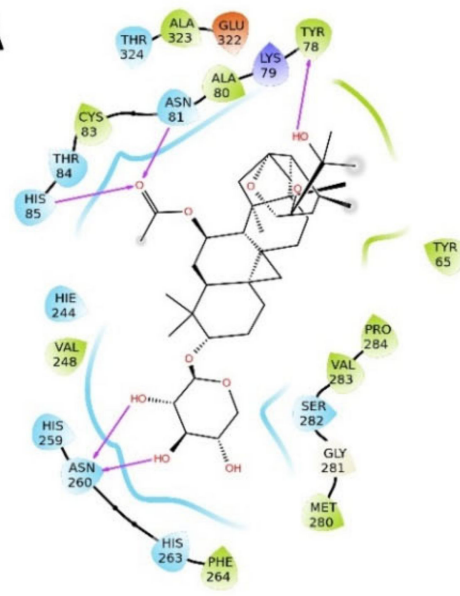

C

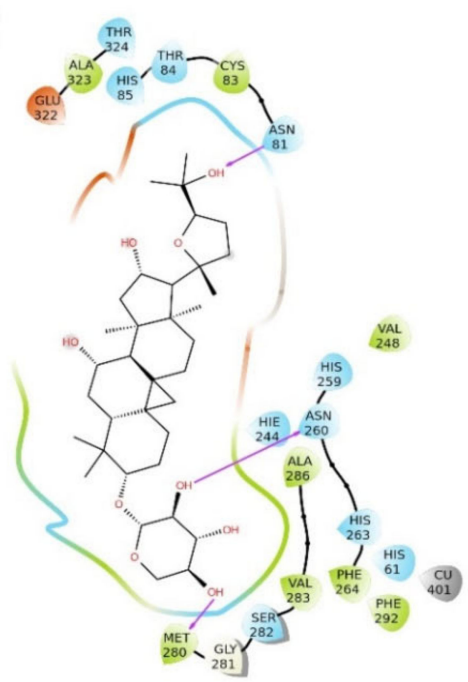

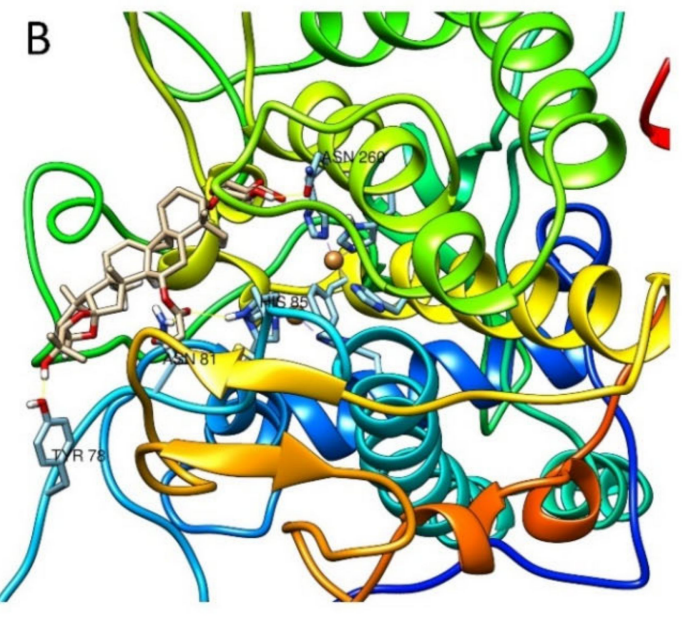

D

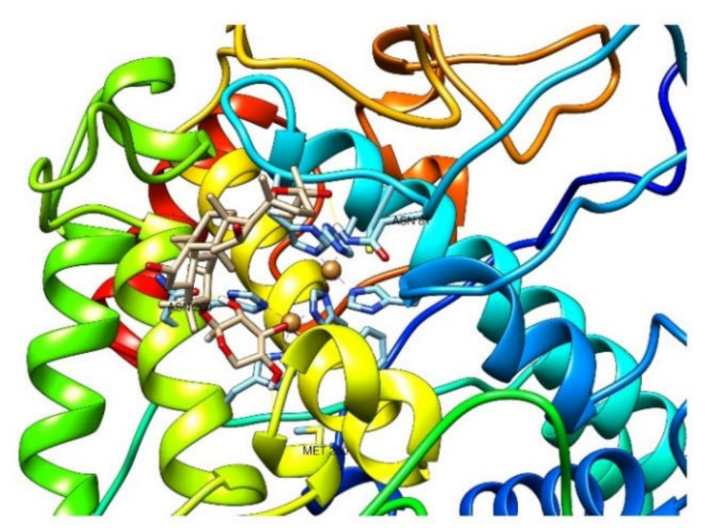

Figure 6. Cont. 


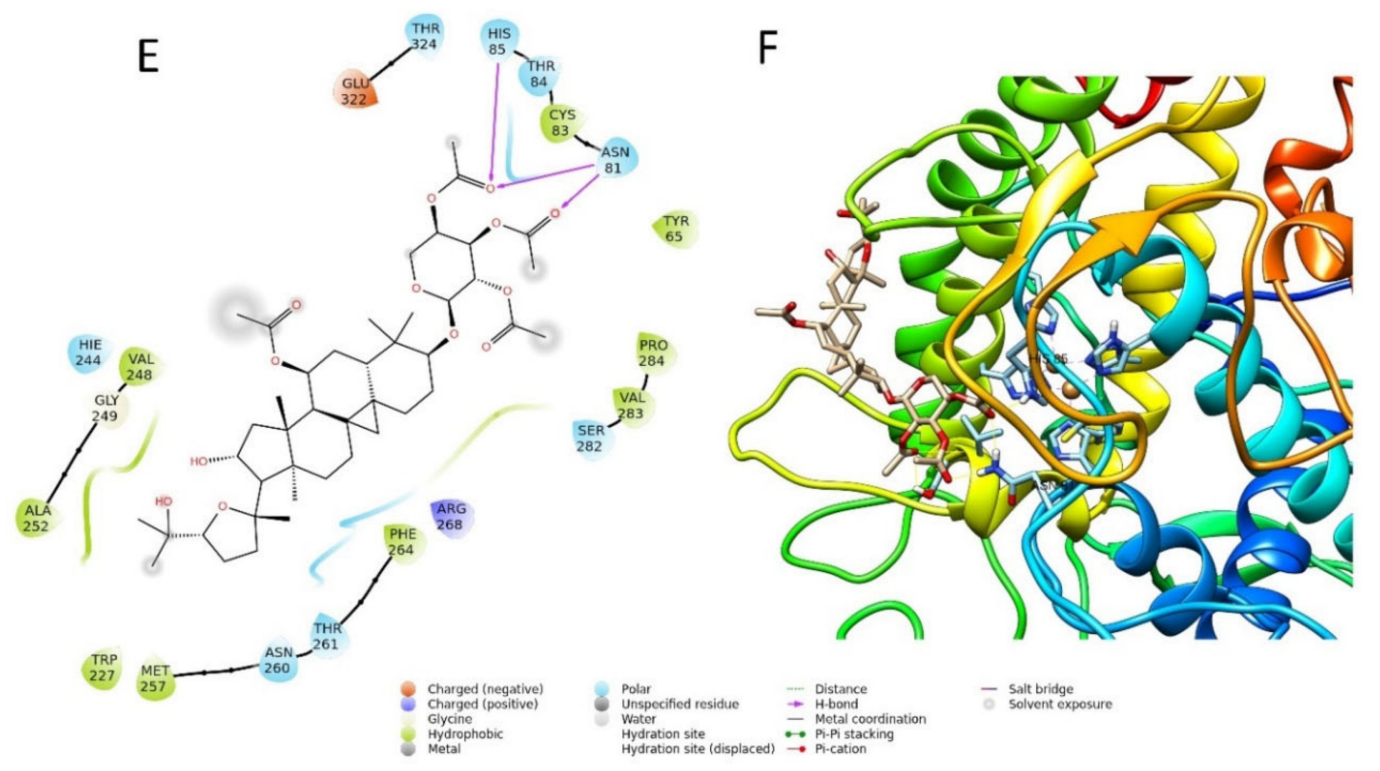

Figure 6. Two-dimensional and three-dimensional docking poses of compound $2(\mathbf{A}, \mathbf{B})$, compound 6 (C,D), and compound $7(\mathbf{E}, \mathbf{F})$.

The best pose of compound 6 , with a docking score of -6.771 , was able to form three interactions with binding site 1 of the enzyme, namely one hydrogen bond to Asn260, one to Asn81, and one to Met280. The $\Delta \mathrm{G}$ free energy was the lowest among the three tested compounds, equal to $-22.238 \mathrm{Kcal} / \mathrm{mol}$. The best pose of compound 7 had the lowest docking score of the series with a value of -4.689 . The $\Delta \mathrm{G}$ free-binding energy was intermediate with a value of $-34.286 \mathrm{Kcal} / \mathrm{mol}$. This molecule was found to form with the enzyme three hydrogen bonds, two to Asn81, and one to His85. Compound 2 was the most active compound, which also obtained the best docking score $(-7.069 \mathrm{Kcal} / \mathrm{mole})$ and could interact with the enzyme through several H-interactions with tyr78, Asn260, His85, and Asn81 as seen in Figure 6. Additionally, its MM-GBSA showed the highest score among the selected compounds, in agreement with the biological activity, equal to $-43.987 \mathrm{Kcal} / \mathrm{mol}$. The docking scores and MM-GBSA calculations of each compound are displayed in Table 3.

Table 3. Docking scores and MM-GBSA values of the selected triterpenoid ligands expressed in $\mathrm{Kcal} / \mathrm{mol}$.

\begin{tabular}{ccc}
\hline Compounds & Docking Scores & MM-GBSA $\Delta$ G-Binding \\
\hline Cycloorbicoside A-7-monoacetate (2) & -7.069 & -43.987 \\
Cycloalpioside D (6) & -6.771 & -34.286 \\
Cycloalpioside D-2', $3^{\prime}, 4^{\prime}, 7$-tetraacetate (7) & -4.698 & -22.238 \\
\hline
\end{tabular}

\subsection{ADMET/TOPKAT Prediction}

Regarding the ADMET prediction, the pharmacokinetic and pharmacodynamic properties of the tested triterpenes were evaluated. Compound 5 was estimated to provide a high human intestinal absorption level, whereas compounds $\mathbf{4}$ and $\mathbf{1 4}$ in this model showed a moderate human intestinal absorption level and thus remained within the $99 \%$ absorption ellipse, as shown in the ADMET plot (Figure 7). Meanwhile, the rest of the compounds revealed low human intestinal absorption levels and likely would require certain semisynthetic modifications or special formulations to increase their absorption to achieve sufficient activity. Regarding solubility, compounds $\mathbf{1}$ and $\mathbf{6 - 1 0}$ displayed good solubility levels in contrast to the rest of the compounds that exerted low solubility. However, the prediction of the penetration of all the compounds through the BBB (blood-brain barrier) 
was undefined, taking level 4, and thus, as illustrated in the ADMET plot in Figure 7, all of the compounds were outside the $99 \%$ BBB confidence ellipse.

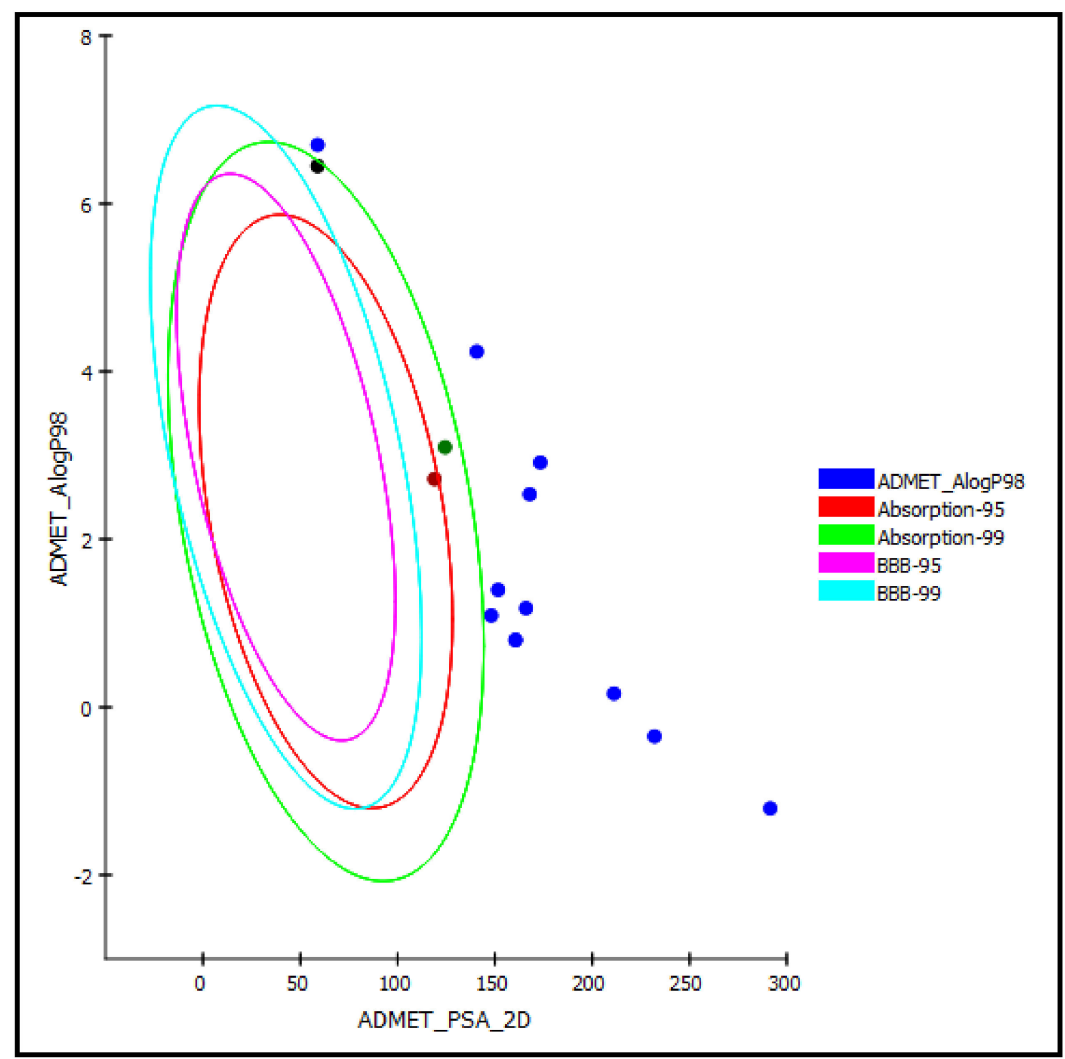

Figure 7. ADMET Plot of the 2D polar surface area (PSA_2D) against calculated ALogP98 for examined triterpenes, showing the $95 \%$ and $99 \%$ confidence limit ellipses corresponding to the blood-brain barrier (BBB) and to the human intestinal absorption models; compound 4 (green dot), compound 5 (red dot), and compound 14 (black dot) are (just) within acceptable boundaries for some penetration in ADMET_AlogP98.

Additionally, the free drug concentration is a critical factor in the evaluation of pharmaceutical activity; thus, the probable binding of compounds to plasma protein should be determined. All triterpenes are expected to have less than 90\% PPB. Cytochrome P450 2D6 (CYP2D6) is an important enzyme in the metabolism of many xenobiotics and thus its inhibition may trigger uncontrolled drug-drug interactions or drug lifetimes. Hence, evaluation of the CYP2D6 inhibition is a crucial part of the process of drug discovery and development. All of the examined triterpenes were considered non-inhibitors of CYP2D6. Additionally, they showed no hepatotoxicity in the Discovery Studio 4.5 hepatotoxic model that postulates the occurrence of dose-dependent human hepatotoxicity (Table 4).

Table 4. The absorption, distribution, metabolism, excretion, and toxicity (ADMET) predictions for the fifteen selected triterpenes.

\begin{tabular}{|c|c|c|c|c|c|c|c|c|}
\hline Compounds & $\begin{array}{l}\text { Absorption } \\
\text { Level }\end{array}$ & $\begin{array}{l}\text { Solubility } \\
\text { Level }\end{array}$ & $\begin{array}{c}\text { BBB } \\
\text { Level }\end{array}$ & $\begin{array}{l}\text { PPB } \\
\text { Level }\end{array}$ & CPY2D6 & Hepatotoxic & PSA-2D & Alog p98 \\
\hline Cycloorbicoside A (1) & 3 & 3 & 4 & False & NI & NT & 160.613 & 0.799 \\
\hline Cycloorbicoside A-7-monoacetate (2) & 3 & 2 & 4 & False & NI & NT & 166.028 & 1.178 \\
\hline 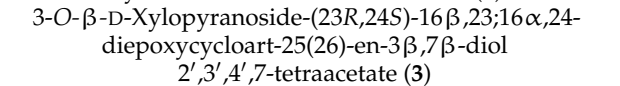 & 2 & 2 & 4 & False & NI & NT & 140.643 & 4.235 \\
\hline $\begin{array}{c}\text { 3-O- } \beta \text {-D-Xylopyranoside-(23R,24S)-16 } \beta, 23 ; 16 \alpha, 24- \\
\text { diepoxycycloart-25(26)-en-3 } \beta, 7 \beta \text {-diol-7-monoacetate (4) }\end{array}$ & 1 & 2 & 4 & False & $\mathrm{NI}$ & NT & 124.397 & 3.097 \\
\hline 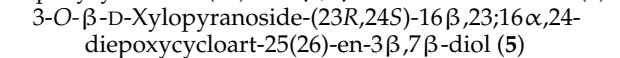 & 0 & 2 & 4 & False & NI & NT & 118.982 & 2.718 \\
\hline Cycloalpioside D (6) & 3 & 3 & 4 & False & NI & NT & 151.683 & 1.398 \\
\hline
\end{tabular}


Table 4. Cont.

\begin{tabular}{|c|c|c|c|c|c|c|c|c|}
\hline Compounds & $\begin{array}{l}\text { Absorption } \\
\text { Level }\end{array}$ & $\begin{array}{l}\text { Solubility } \\
\text { Level }\end{array}$ & $\begin{array}{l}\text { BBB } \\
\text { Level }\end{array}$ & $\begin{array}{l}\text { PPB } \\
\text { Level }\end{array}$ & CPY2D6 & Hepatotoxic & PSA-2D & Alog p98 \\
\hline Cycloalpioside D-2', $3^{\prime}, 4^{\prime}, 7$-tetraacetate (7) & 3 & 3 & 4 & False & NI & NT & 173.344 & 2.915 \\
\hline Cycloalpioside D-2', $3^{\prime}, 4^{\prime}$-triacetate (8) & 3 & 3 & 4 & False & NI & NT & 167.929 & 2.536 \\
\hline $\begin{array}{l}\text { 3-O- } \beta \text {-D-Xylopyranoside-20R-25-norcycloartan-3 } 3,7 \beta, 16 \beta \text { - } \\
\text { triol-20,24-olide (9) }\end{array}$ & 2 & 3 & 4 & False & NI & NT & 148.168 & 1.092 \\
\hline Cycloorbicoside B (10) & 3 & 3 & 4 & False & NI & NT & 160.63 & 0.162 \\
\hline Cyclosieversioside E (11) & 3 & 2 & 4 & False & NI & NT & 211.174 & -0.348 \\
\hline Astragaloside IV (12) & 3 & 2 & 4 & False & NI & NT & 231.99 & -1.207 \\
\hline Cyclosieversioside H (13) & 3 & 2 & 4 & False & NI & NT & 291.481 & 6.447 \\
\hline Oleanolic acid (14) & 1 & 1 & 4 & False & NI & NT & 58.931 & 6.699 \\
\hline Ursolic acid (15) & 2 & 1 & 4 & False & NI & NT & 58.931 & 0.799 \\
\hline
\end{tabular}

Note that 0,1,2, and 3 indicates good, moderate, low, and very low absorption, respectively; 0, 1, 2, 3, 4, and 5 indicates extremely low, very low but possible, low, good, optimal, and too high solubility, respectively; $0,1,2,3$, and 4 denote very high, high, medium, low, and undefined penetration through the BBB, respectively. FALSE means less than $90 \%$ and TRUE means more than $90 \%$. in PPB (plasma protein binding) NI: non-inhibitor; NT: non-toxic; PSA 2D: 2D polar surface area; and AlogP98: the logarithm of the partition coefficient between $n$-octanol and water.

Regarding the TOPKAT prediction, all of the tested compounds revealed to be nonmutagenic concerning the prediction of chemical Ames mutagenicity performed in silico. Additionally, all showed no carcinogenicity in both male and female rat NTP (National Toxicology Program) models, performed by Discovery Studio 4.5 in silico, except oleanolic acid (14) which revealed potential carcinogenicity to male rat NTP. They displayed rat oral LD50 ranging between 0.98 and $7.88 \mathrm{~g} / \mathrm{kg}$ of body weight, wherein the lowest LD50 was exerted by compound $3(0.98 \mathrm{~g} / \mathrm{kg}$ of body weight) and the highest LD50 (7.88 g/ $/ \mathrm{kg}$ of body weight) was displayed by 13. Regarding skin irritancy, all of the tested compounds revealed mild skin irritancy, except compounds 6, 9, and 13-15 that displayed moderate irritation to the skin. Regarding ocular irritation, compounds $2-5$ and $\mathbf{9}$ showed no ocular irritation. In contrast, severe irritation was predicted for the aglycones oleanolic acid (14) and ursolic acid (15). However, all of the other compounds showed only moderate irritation. Thus, from the ADMET/TOPKAT prediction, compounds $\mathbf{4}$ and $\mathbf{5}$ are expected to display the best pharmacokinetic and pharmacodynamic behavior with no mutagenic, carcinogenic, or irritant effects, combined with low LD50. They also revealed considerable activity in most of the examined activities. In other cases, triterpenes and triterpene glycosides may require modifications to enhance their pharmacokinetics and pharmacodynamics, particularly those that revealed high activity (Table 5).

Table 5. TOPKAT analysis of the fifteen selected triterpenes.

\begin{tabular}{|c|c|c|c|c|c|c|}
\hline Compounds & $\begin{array}{l}\text { Ames } \\
\text { Prediction }\end{array}$ & $\begin{array}{l}\text { Rat Oral LD50 g/kg } \\
\text { of Body Weight }\end{array}$ & $\begin{array}{c}\text { Skin } \\
\text { Irritancy }\end{array}$ & $\begin{array}{l}\text { Ocular } \\
\text { Irritancy }\end{array}$ & Female Rat NTP & Male Rat NTP \\
\hline Cycloorbicoside A (1) & Non-mutagen & 2.18 & Mild & Moderate & Non-carcinogen & Non-carcinogen \\
\hline $\begin{array}{l}\text { Cycloorbicoside A-7-monoacetate (2) } \\
\text { 3-O- } \beta \text {-D-Xylopyranoside-(23R,24S)- }\end{array}$ & Non-mutagen & 2.06 & Mild & None & Non-carcinogen & Non-carcinogen \\
\hline $\begin{array}{c}16 \beta, 23 ; 16 \alpha, 24 \text {-diepoxycycloart-25(26)-en- } 3 \beta, 7 \beta \text { - } \\
\text { diol } 2^{\prime}, 3^{\prime}, 4^{\prime}, 7 \text {-tetraacetate (3) }\end{array}$ & Non-mutagen & 0.98 & Mild & None & Non-carcinogen & Non-carcinogen \\
\hline $\begin{array}{l}\text { 3-O- } \beta \text {-D-Xylopyranoside-(23R,24S)- } \\
16 \beta, 23 ; 16 \alpha, 24 \text {-diepoxycycloart-25(26)-en-3 } \beta, 7 \beta \text { - } \\
\text { diol-7-monoacetate (4) }\end{array}$ & Non-mutagen & 1.32 & Mild & None & Non-carcinogen & Non-carcinogen \\
\hline $\begin{array}{c}\text { 3-O- } \beta \text {-D-Xylopyranoside-(23R,24S)- } \\
16 \beta, 23 ; 16 \alpha, 24 \text {-diepoxycycloart-25(26)-en-3 } \beta, 7 \beta \text { - } \\
\text { diol (5) }\end{array}$ & Non-mutagen & 1.39 & Mild & None & Non-carcinogen & Non-carcinogen \\
\hline Cycloalpioside D (6) & Non-mutagen & 3.06 & Moderate & Moderate & Non-carcinogen & Non-carcinogen \\
\hline Cycloalpioside D-2' $, 3^{\prime}, 4^{\prime}, 7$-tetraacetate (7) & Non-mutagen & 1.23 & Mild & Moderate & Non-carcinogen & Non-carcinogen \\
\hline Cycloalpioside D-2' $3^{\prime}, 4^{\prime}$-triacetate $(8)$ & Non-mutagen & 1.70 & Mild & Moderate & Non-carcinogen & Non-carcinogen \\
\hline $\begin{array}{c}\text { 3-O- } \beta \text {-D-Xylopyranoside-20R-25-norcycloartan- } \\
3 \beta, 7 \beta, 16 \beta \text {-triol-20,24-olide (9) }\end{array}$ & Non-mutagen & 2.09 & Moderate & None & Non-carcinogen & Non-carcinogen \\
\hline Cycloorbicoside B (10) & Non-mutagen & 2.18 & Mild & Moderate & Non-carcinogen & Non-carcinogen \\
\hline Cyclosieversioside E (11) & Non-mutagen & 5.80 & Mild & Moderate & Non-carcinogen & Non-carcinogen \\
\hline Astragaloside IV (12) & Non-mutagen & 7.56 & Mild & Moderate & Non-carcinogen & Non-carcinogen \\
\hline Cyclosieversioside H (13) & Non-mutagen & 7.88 & Moderate & Moderate & Non-carcinogen & Non-carcinogen \\
\hline Oleanolic acid (14) & Non-mutagen & 1.12 & Moderate & Severe & Non-carcinogen & Carcinogen \\
\hline Ursolic acid (15) & Non-mutagen & 0.80 & Moderate & Severe & Non-carcinogen & Non-Carcinogen \\
\hline
\end{tabular}




\section{Materials and Methods}

\subsection{Triterpenes Used in This Study}

Triterpenes and their derivatives (1-11 and 13) obtained from the Institute of the Chemistry of Plant Substances (Tashkent, Uzbekistan) were used in this study with purities > 95\%. Compounds 12 and 14-15 were purchased from Merck, Darmstadt, Germany. They were cycloorbicoside A (1), cycloorbicoside A-7-monoacetate (2), 3- $O$ - $\beta$-D-xylopyranoside(23R,24S)-16 $\beta, 23 ; 16 \alpha, 24$-di-epoxycycloart-25(26)-en-3 $\beta, 7 \beta$-diol $2^{\prime}, 3^{\prime}, 4^{\prime}, 7$-tetraacetate (3), 3-O- $\beta$-D-xylopyranoside-(23R,24S)-16 $\beta, 23$; 16 $\alpha, 24$-diepoxycycloart-25(26)-en-3 $\beta, 7 \beta$-diol 7monoacetate (4), 3-O- $\beta$-D-xylopyranoside-(23R,24S)-16 $\beta, 23 ; 16 \alpha, 24$-diepoxycycloart-25(26)en-3 $\beta, 7 \beta$-diol (5), cycloalpioside D (6), cycloalpioside D-2' $3^{\prime}, 4^{\prime}, 7$-tetraacetate (7), cycloalpioside D -2', $3^{\prime}, 4^{\prime}$-triacetate (8), 3-O- $\beta$-D-xylopyronoside-20R-25-norcycloartan-3 $\beta, 7 \beta, 16 \beta$ triol-20,24-olide (9), cycloorbicoside B (10), cyclosiversioside E (11), astragaloside IV (syn. cyclosieversioside F, astrasieversianin XIV) (12), cyclosiversioside $\mathrm{H}$ (13), oleanolic acid (14), and ursolic acid (15).

\subsection{In Vitro Assays for the Evaluation of the Antioxidant Activity of the Studied Triterpenes 3.2.1. Total Antioxidant Activity by the Phosphomolybdenum Method}

The total antioxidant activity for all the studied compounds was determined by using the phosphomolybdenum assay and adopting a protocol described by Zengin et al. (2015) [28]. In total, $0.3 \mathrm{~mL}$ of each compound studied was added to $3 \mathrm{~mL}$ of the reagent solution containing $4 \mathrm{mM}$ of ammonium molybdate, $28 \mathrm{mM}$ of sodium phosphate, and $0.6 \mathrm{M}$ of sulfuric acid. After incubation for $90 \mathrm{~min}$ at $95^{\circ} \mathrm{C}$, the absorbance of the sample was measured at $695 \mathrm{~nm}$. The Trolox equivalent (mg TE/g) was used to express the total antioxidant capacity.

\subsubsection{1,1-Diphenyl-2-Picrylhydrazyl (DPPH*) Radical Scavenging Capacity Assay}

The $\mathrm{DPPH}^{*}$ radical scavenging capacity of the examined samples was determined by adopting the method previously described by Sarikurkcu et al., (2011) [29,30]. In total, $1 \mathrm{~mL}$ of the tested sample was added to $4 \mathrm{~mL}$ of the $\mathrm{DPPH}^{*}$ methanol solution $(0.004 \%)$. After incubation of the samples in the dark at room temperature for $30 \mathrm{~min}$, the absorbance of the sample was determined at $517 \mathrm{~nm}$. The Trolox equivalent (mg TE/g) was used to express the $\mathrm{DPPH}^{*}$ radical scavenging activity.

\subsubsection{2,2'-Azinobis(3-Ethylbenzothiazoline)-6-Sulfonic Acid (ABTS) Cation Radical Scavenging Activity}

As previously described by Re et al. (1999), ABTS cation radical scavenging activity was evaluated, accompanied by certain modifications [31]. The reaction of $2.45 \mathrm{mM}$ of potassium persulfate with $7 \mathrm{mM}$ of $\mathrm{ABTS}+{ }^{*}$ solution resulted in the direct production of the $\mathrm{ABTS}+{ }^{*}$ radical cation. This reaction occurs at room temperature in the dark for 12-16 h. Dilution of the ABTS+* solution using methanol was performed before starting the assay to reach an absorbance of $0.700 \pm 0.02$ at $734 \mathrm{~nm}$. In total, $1 \mathrm{~mL}$ of the sample was combined and mixed with $2 \mathrm{~mL}$ of the prepared ABTS+ ${ }^{*}$ solution. After incubation of the samples at room temperature for $30 \mathrm{~min}$, the absorbance of the sample was determined at $734 \mathrm{~nm}$. The Trolox equivalent (mg TE/g) was used to express the ABTS radical cation scavenging activity.

\subsubsection{Cupric Ion-Reducing Activity (CUPRAC) Assay}

The cupric ion-reducing activity (CUPRAC) was performed by following a protocol reported by Zengin et al. (2014) [32]. In total, $0.5 \mathrm{~mL}$ of the sample was added to a reaction mixture composed of $\mathrm{NH}_{4} \mathrm{Ac}$ buffer $(1 \mathrm{~mL}, 1 \mathrm{M}, \mathrm{pH} 7.0)$, neocuproine $(1 \mathrm{~mL}, 7.5 \mathrm{mM})$, and $\mathrm{CuCl}_{2}(1 \mathrm{~mL}, 10 \mathrm{mM})$. Similarly, the blank solution was prepared by adding $0.5 \mathrm{~mL}$ of the sample to a reaction mixture free from $\mathrm{CuCl}_{2}$. After incubation of the samples at room temperature for $30 \mathrm{~min}$, the absorbance of both the sample and blank was measured at 
$450 \mathrm{~nm}$, and then subtraction of the blank absorbance from the sample was performed. The Trolox equivalent (mg TE/g) was used to express CUPRAC activity.

\subsubsection{Ferric-Reducing Antioxidant Power (FRAP) Assay}

The FRAP assay was performed as reported by Aktumsek et al., accompanied by certain modifications [33]. In total, $0.1 \mathrm{~mL}$ of the sample was added to $2 \mathrm{~mL}$ of the FRAP reagent, which was composed of $10 \mathrm{mM}$ of 4,6-tris(2-pyridyl)-s-triazine (TPTZ) and acetate buffer $(0.3 \mathrm{M}, \mathrm{pH} 3.6)$ premixed with $20 \mathrm{mM}$ of ferric chloride and $\mathrm{HCl}(40 \mathrm{mM})$ in a ratio of 1:10:1 $(\mathrm{v} / \mathrm{v} / \mathrm{v})$. After incubation of the samples at room temperature for $30 \mathrm{~min}$, the absorbance of the sample was measured at $593 \mathrm{~nm}$. The Trolox equivalent $(\mathrm{mg}$ TE/g) was used to express FRAP activity.

\subsubsection{Metal-Chelating Activity on Ferrous Ions}

The metal-chelating activity on ferrous ions was measured as previously reported by Aktumsek et al. [33]. In total, $2 \mathrm{~mL}$ of the tested samples were mixed with $0.05 \mathrm{~mL}$ of $2 \mathrm{mM}$ of ferric chloride solution. The initiation of the reaction was achieved via the addition of $0.2 \mathrm{~mL}$ of ferrozine $(5 \mathrm{mM})$. Similarly, the blank preparation was done by adding $2 \mathrm{~mL}$ of the tested samples to $0.05 \mathrm{~mL}$ of $2 \mathrm{mM}$ of ferric chloride solution and $0.2 \mathrm{~mL}$ of water without ferrozine. After incubation of the samples at room temperature for $10 \mathrm{~min}$, the absorbance of both the sample and blank was measured at $562 \mathrm{~nm}$, and then subtraction of the blank absorbance from the sample was performed. The EDTA equivalent (mg EDTAE/g) was used to express the metal-chelating activity.

\subsection{In Vitro Assays for the Evaluation of the Enzyme Inhibitory Activity of the Studied Triterpenes}

\subsubsection{Cholinesterase (ChE) Inhibitory Activity}

The ChE inhibitory potential was determined using Ellman's method as described by Aktumsek et al., accompanied by certain modifications [33]. In total, $50 \mu \mathrm{L}$ of the tested samples were added to $125 \mu \mathrm{L}$ of DTNB and $25 \mu \mathrm{L}$ of acetyl (AChE) or butyryl cholinesterase (BChE) in $25 \mu \mathrm{L}$ of Tris- $\mathrm{HCl}$ buffer ( $\mathrm{pH}$ 8.0) in a 96-well microplate, followed by their incubation at $25^{\circ} \mathrm{C}$ for $15 \mathrm{~min}$. The reaction was initiated via the addition of $25 \mu \mathrm{L}$ of acetylthiocholine iodide (ATCI) or butyrylthiocholine chloride (BTCl). Similarly, blank preparation was done by mixing the samples with all of the reagents previously mentioned, except for the enzyme solutions ( $\mathrm{AChE}$ or $\mathrm{BChE}$ ). After incubation of the samples at $25^{\circ} \mathrm{C}$ for $10 \mathrm{~min}$, the absorbance of both the sample and blank was measured at $405 \mathrm{~nm}$, and then subtraction of the blank absorbance from the sample was performed. The Galanthamine equivalent (mg GALAE/g) equivalent was used to express the cholinesterase inhibitory activity. Note: (Absorbance $(\mathrm{A})=0.0607(\mu \mathrm{g}$ galanthamine $)+0.4746,(\mathrm{R} 2=0.9404)$ for $\mathrm{AChE}$ and $\mathrm{A}=1.5806(\mu \mathrm{g}$ galanthamine $)+0.2839,(\mathrm{R} 2=0.9993)$ for $\mathrm{BuChE})[19,34]$.

\subsubsection{Tyrosinase Inhibitory Activity}

The tyrosinase inhibitory potential was determined by applying the modified dopachrome assay using l-DOPA as a substrate, as described by Zengin et al. (2014) [32], accompanied by certain modifications. In total, $25 \mu \mathrm{L}$ of the sample was added to $40 \mu \mathrm{L}$ of tyrosinase solution and $100 \mu \mathrm{L}$ of phosphate buffer $(\mathrm{pH}$ 6.8) in a 96-well microplate, followed by their incubation at $25^{\circ} \mathrm{C}$ for $15 \mathrm{~min}$. Initiation of the reaction was done via the addition of $40 \mu \mathrm{L}$ of l-DOPA. Similarly, preparation of blank sample was done by mixing the sample with all of the reagents previously mentioned, except for the enzyme solution. After incubation of the samples at $25{ }^{\circ} \mathrm{C}$ for $10 \mathrm{~min}$, the absorbance of both the sample and blank was measured at $492 \mathrm{~nm}$, and then subtraction of the blank absorbance from the sample was performed. The Kojic acid (mg KAE/g) equivalent was used to express the tyrosinase inhibitory activity, where $\mathrm{A}=0.0775(\mu \mathrm{g}$ kojic acid $)+0.0163, \mathrm{R} 2=0.9974)$. 


\subsection{3. $\alpha$-Amylase Inhibitory Activity}

The $\alpha$-Amylase inhibitory activity was employed using the Caraway-Somogyi iodine/potassium iodide (IKI) assay as previously reported by Lazarova et al., 2015 [35], accompanied by certain modifications. In total, $25 \mu \mathrm{L}$ of the sample was added to $50 \mu \mathrm{L}$ of $\alpha$-amylase solution in phosphate buffer ( $\mathrm{pH}$ 6.9) with sodium chloride $(6 \mathrm{mM})$ in a 96 -well microplate, followed by their incubation at $37^{\circ} \mathrm{C}$ for $10 \mathrm{~min}$. Initiation of the reaction was done via the addition of $50 \mu \mathrm{L}$ of starch solution. Similarly, the preparation of the blank was done by mixing the sample with all of the reagents previously mentioned, except for the enzyme solution. After incubation of the samples at $37^{\circ} \mathrm{C}$ for $10 \mathrm{~min}$, stopping of the reaction was achieved by the addition of $25 \mu \mathrm{L}$ of $1 \mathrm{mM}$ of $\mathrm{HCl}$, that was consequently followed by the addition of $100 \mu \mathrm{L}$ of iodine-potassium iodide solution. The absorbance of both the sample and blank was measured at $630 \mathrm{~nm}$, and then subtraction of the blank absorbance from the sample was performed. The Acarbose (mg ACAEs/g) equivalent was used to express $\alpha$-amylase inhibitory activity, where $\mathrm{A}=0.9094$ (mg acarbose) +1.2921 , $\mathrm{R} 2=0.9979)$.

\subsection{4. $\alpha$-Glucosidase Inhibitory Activity}

Determination of the $\alpha$-glucosidase inhibitory activity was achieved by employing the assay previously reported by Lazarova et al., 2015 [35], accompanied by certain modifications. In total, $50 \mu \mathrm{L}$ of the sample was added to $50 \mu \mathrm{L}$ of glutathione and $50 \mu \mathrm{L}$ of enzyme solution in phosphate buffer ( $\mathrm{pH}$ 6.8) with $50 \mu \mathrm{L}$ of PNPG in a 96-well microplate, followed by their incubation at $37^{\circ} \mathrm{C}$ for $15 \mathrm{~min}$. Similarly, blank preparation was done by mixing the sample with all of the reagents previously mentioned, except for the $\alpha$-glucosidase enzyme solution. Stopping of the reaction was achieved by the addition of $50 \mu \mathrm{L}$ of $0.2 \mathrm{mM}$ of $\mathrm{HCl}$. The absorbance of both the sample and blank was measured at $400 \mathrm{~nm}$, and then subtraction of the blank absorbance from the sample was performed. The acarbose (mg ACAE/g) equivalent was used to express $\alpha$-glucosidase inhibitory activity, where $\mathrm{A}=2.1183(\mathrm{mg}$ acarbose $)-0.2336, \mathrm{R} 2=0.9410$.

\subsection{Molecular Modelling Study}

\subsubsection{Preparation of the Enzyme}

The mushroom tyrosinase structure (PDB ID 2Y9X; $2.78 \AA$ ) [36] was selected for the docking experiments considering the in vitro assays which revealed very good inhibitory activity on this target, and thus was more relevant than for the other enzymatic targets (see Figures 3 and 4). The raw crystallographic enzyme file was polished and prepared for docking by the PrepWizard module embedded in Maestro Schrödinger (2017), which was set to remove the non-catalytic water and all the other molecules included in the PDB file. The enzyme's crystal structure was minimized at $\mathrm{pH} 7.4$ by PROPKA following the well-established procedure used by our research group [37].

\subsubsection{Preparation of the Ligand}

The in silico studies were performed on the most active compounds on tyrosinase, namely compounds $\mathbf{2}, \mathbf{6}$, and $\mathbf{7}$, as mentioned above, which belong to the triterpenoid family. Before the docking experiments, the ligands as drawn manually through the Maestro 3D builder tool and starting from the base molecule of cyclosieversioside downloaded from the Zinc12 database with id:ZINC253916001—were prepared by the LigPrep tool placed in Maestro 10.1, neutralized at pH 7.4 by Epik, and minimized by force field OPLS3. The chemical structures of the ligand are depicted in Figure 1.

\subsubsection{Molecular Docking Experiments}

The tyrosinase model was prepared using Maestro 10.2, protonated at neutral $\mathrm{pH}$, and all the crystals errors were corrected automatically. The docking experiments were carried out by using Glide [38], firstly using the scoring function Standard Precision (SP) and then eXtra Precision (XP); the ligand was set to be flexible, whereas the enzyme structure 
was kept rigid. The docking grid was automatically calculated by Glide, centered on the crystallographic ligand or on the site map results (Figure 5), and was extended in a box of $26 \times 26 \times 26$ angstrom. Both $\mathrm{Cu}$ atoms were indicated as suitable for coordinative bonds. The docking was set to allow for passing through the initial Glide screens' 10,000 poses and then the software retained the first 500, on which a post-docking energy minimization was performed, after which only the best-ranked one was shown.

3.4.4. Molecular Mechanics Energies Combined with Generalized Born and Surface Area Continuum Solvation (MM-GBSA)

The obtained docking poses were submitted to the binding energy estimation by the MM-GBSA method of the Prime module set in Maestro 10.1.

\subsubsection{Site Maps}

The binding site analysis was performed using the SiteMap tool of the Schrodinger software. SiteMap identified five sites based on the site score, which includes size, volume, amino acid exposure, enclosure, contact, hydrophobicity, hydrophilicity, and donor/acceptor ratio. The search was set to recognize each possible binding site with a minimum of 15 site points; then, the grid was set to "fine" and the definition of hydrophobicity was set as "more restrictive" [39].

\subsection{ADMET/TOPKAT Prediction}

In this study, the triterpenes were subjected to ADMET prediction (absorption, distribution, metabolism, excretion, and toxicity) and toxicity prediction (TOPKAT) using Discovery Studio 4.5 (Accelrys Inc., San Diego, CA, USA). Blood-brain barrier penetration (BBB), aqueous solubility, plasma protein binding prediction (PPB), cytochrome P450 2D6, hepatotoxicity level, and human intestinal absorption (HIA) were chosen as descriptors of the ADMET prediction. Meanwhile, Ames mutagenicity, eye and skin irritation, carcinogenic effect on male and female rat NPT, and rat oral LD50 were chosen as parameters in the TOPKAT prediction to select entities with considerable pharmacokinetics behavior with concomitant low toxicity [37].

\subsection{Statistical Analysis}

All experiments were performed in triplicates and the results are expressed as mean \pm SD (standard deviation). Variations among the different tested compounds were analyzed by using one-way variance analysis (ANOVA), followed by Tukey's honest significant difference post-hoc test with $=0.05$ using the SPSS version 14.0 program. Graphs were drawn using GraphPad Prism 5 (GraphPad Software Inc., San Diego, CA, USA).

\section{Conclusions}

Triterpenes represent a large category of naturally occurring compounds possessing many significant biological activities sometimes in the form of aglycones but often only or more specifically in the form of various glycosides. There is an increasing interest in natural triterpenoids due to their outstanding biological activities, as exemplified by their anticancer, antiviral, bactericidal, spermicidal, anti-allergic, fungicidal, and cardiovascular protective effects. The antioxidant and enzyme inhibitory potential of fifteen triterpenes of the cycloartane type was investigated using different assays. Most of the tested compounds showed antioxidant activities, although they did not contain the typical phenolic or catecholic moieties found, e.g., in plant flavonoids. The different assays reflected also different modes of antioxidant activity. All triterpenes showed AChE and BChE inhibitory potential, likely due to a general binding in the large lipophilic pocket and because of variable inhibitory activities towards $\alpha$-amylase, $\alpha$-glucosidase, and tyrosinase enzymes, with the latter further supported by in silico studies. While most glycoside effects, similar to those on the cholinesterases, appeared to be unspecific, tyrosinase inhibition showed clear differentiation between different compounds and appeared to be promising, espe- 
cially since these lipo and amphiphilic triterpenes could show sufficient skin penetration for activity. From the ADMET/TOPKAT prediction, it can be concluded that $3-O-\beta-D-$

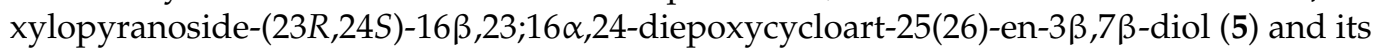
7 -acetate (4) are likely to display the best pharmacokinetic and pharmacodynamic behavior with no mutagenic, carcinogenic, or irritant effects to be expected, as well as with low LD50. However, the most active substances in the in vitro test revealed to be compound 2 , 6, and $\mathbf{7}$ for tyrosinase, while compounds 3-8 were moderate inhibitors of $\alpha$-glucosidase, with scarce inhibition on $\alpha$-amylase, and compounds 1-7 and 9 were moderately active on AChE. Overall, these triterpenes reveal some general inhibitory activity but also some have more specific effects (somewhat similar to another large natural products group, specifically the flavonoids, which also have some general, e.g., antioxidant, but also sometimes very specific, effects). Semisynthetic modification of such triterpenes can help to enhance both their specificity and their pharmacokinetic and pharmacodynamic properties. In particular, those that revealed high basic activity can be employed as leads for the mild natural product-based (co-)treatment of early stage Alzheimer's disease and diabetes, and is the most promising against skin hyperpigmentation. It should be noted here that the inhibitors of tyrosinase are often used for skin treatment and are administered by topical applications, thus poor pharmacokinetic properties of compound $\mathbf{2}$ should be not considered as a limit regarding its development as an antityrosinae agent.

Author Contributions: N.Z.M., conceptualization, provided the compounds, and wrote the first draft; F.S.Y., performed the ADMET/TOPKAT prediction and wrote the draft; H.H., helped in writing the manuscript; G.Z., performed antioxidant and enzyme inhibition assays; A.M., performed the docking studies; N.M.A.M. and M.L.A., obtained funding and supported in the writing of the manuscript; B.W. and L.A.W., project administration, supervision, and revision of the manuscript. All authors have read and agreed to the published version of the manuscript.

Funding: This research study was funded by the King Saud University Researchers Supporting Project, number RSP-2021/294, King Saud University, Riyadh, Saudi Arabia.

Institutional Review Board Statement: Not applicable.

Informed Consent Statement: Not applicable.

Data Availability Statement: All data are available in this study.

Acknowledgments: All authors would like to thank the King Saud University Researchers Supporting Project, number RSP-2021/294, King Saud University, Riyadh, Saudi Arabia. The authors (N.Z.M. and H.H.) thank the Alexander von Humboldt Foundation for providing the opportunity to engage in research work in Wessjohann's Laboratory in Germany. We thank Mamed Isaev for providing the triterpenes.

Conflicts of Interest: The authors declare no conflict of interest.

Sample Availability: Samples of some compounds are available from the authors.

\section{References}

1. Finaud, J.; Lac, G.; Filaire, E. Oxidative stress. Sports Med. 2006, 36, 327-358. [CrossRef]

2. Pepe, H.; Balci, Ş.S.; Revan, S.; Akalin, P.P.; Kurtoğlu, F. Comparison of oxidative stress and antioxidant capacity before and after running exercises in both sexes. Gender. Med. 2009, 6, 587-595. [CrossRef] [PubMed]

3. Lennicke, C.; Rahn, J.; Lichtenfels, R.; Wessjohann, L.A.; Seliger, B. Hydrogen peroxide-production, fate and role in redox signaling of tumor cells. Cell Commun. Signal. 2015, 13, 1-19. [CrossRef] [PubMed]

4. Thabet, A.A.; Youssef, F.S.; El-Shazly, M.; El-Beshbishy, H.A.; Singab, A.N.B. Validation of the antihyperglycaemic and hepatoprotective activity of the flavonoid rich fraction of Brachychiton rupestris using in vivo experimental models and molecular modelling. Food Chem.Toxicol. 2018, 114, 302-310. [CrossRef]

5. Petersen, R.C. Alzheimer's disease: Progress in prediction. Lancet. Neurol. 2010, 9, 4-5. [CrossRef]

6. Ummat, V.; Tiwari, B.K.; Jaiswal, A.K.; Condon, K.; Garcia-Vaquero, M.; O'Doherty, J.; O'Donnell, C.; Rajauria, G. Optimisation of ultrasound frequency, extraction time and solvent for the recovery of polyphenols, phlorotannins and associated antioxidant activity from brown seaweeds. Marine Drugs. 2020, 18, 250. [CrossRef] 
7. Li, R.; Ru, Y.; Wang, Z.; He, X.; Kong, K.-W.; Zheng, T.; Zhang, X. Phytochemical composition, antioxidant activity, and enzyme inhibitory activities ( $\alpha$-glucosidase, xanthine oxidase, and acetylcholinesterase) of Musella lasiocarpa. Molecules 2021, $26,4472$. [CrossRef]

8. Mattioli, R.; Francioso, A.; d’Erme, M.; Trovato, M.; Mancini, P.; Piacentini, L.; Casale, A.M.; Wessjohann, L.; Gazzino, R.; Costantino, P. Anti-inflammatory activity of a polyphenolic extract from Arabidopsis thaliana in vitro and in vivo models of Alzheimer's disease. Int. J. Mol. Sci. 2019, 20, 708. [CrossRef] [PubMed]

9. Farag, M.A.; Sakna, S.T.; El-Fiky, N.M.; Shabana, M.M.; Wessjohann, L.A. Phytochemical, antioxidant and antidiabetic evaluation of eight Bauhinia L. species from Egypt using UHPLC-PDA-qTOF-MS and chemometrics. Phytochemistry 2015, 119, 41-50. [CrossRef] [PubMed]

10. Santiago, L.A.; Mayor, A.B.R. Lupeol: An antioxidant triterpene in Ficus pseudopalma Blanco (Moraceae). Asian Paci. J. Trop. Biomed. 2014, 4, 109-118. [CrossRef]

11. Mamadalieva, N.Z.; Youssef, F.S.; Ashour, M.L.; Sasmakov, S.A.; Tiezzi, A.; Azimova, S.S. Chemical composition, antimicrobial and antioxidant activities of the essential oils of three Uzbek Lamiaceae species. Nat. Prod. Res. 2019, 33, 2394-2397. [CrossRef]

12. Aboulwafa, M.M.; Youssef, F.S.; Gad, H.A.; Altyar, A.E.; Al-Azizi, M.M.; Ashour, M.L. A comprehensive insight on the health benefits and phytoconstituents of Camellia sinensis and recent approaches for its quality control. Antioxidants 2019, 8, 455. [CrossRef]

13. Patocka, J. Biologically active pentacyclic triterpenes and their current medicine signification. J. Appl. Biomed. 2003, 1, 7-12 [CrossRef]

14. Hussain, H.; Ali, I.; Wang, D.; Hakkim, F.L.; Westermann, B.; Rashan, L.; Ahmed, I.; Green, I.R. Boswellic acids: Privileged structures to develop lead compounds for anticancer drug discovery. Expert Opin. Drug Dis. 2021, 16, 851-867. [CrossRef] [PubMed]

15. Hussain, H.; Ali, I.; Wang, D.; Hakkim, F.L.; Westermann, B.; Ahmed, I.; Ashour, A.M.; Khan, A.; Hussain, A.; Green, I.R. Glycyrrhetinic acid: A promising scaffold for the discovery of anticancer agents. Expert Opin. Drug Dis. 2021. [CrossRef]

16. Rodríguez-Díaz, M.; Delporte, C.; Cartagena, C.; Cassels, B.K.; González, P.; Silva, X.; León, F.; Wessjohann, L.A. Topical anti-inflammatory activity of quillaic acid from Quillaja saponaria Mol. and some derivatives. J. Pharm. Pharmacol. 2011, 63, 718-724.

17. Farag, M.A.; Weigend, M.; Luebert, F.; Brokamp, G.; Wessjohann, L.A. Phytochemical, phylogenetic, and anti-inflammatory evaluation of 43 Urtica accessions (stinging nettle) based on UPLC-Q-TOF-MS metabolomic profiles. Phytochemistry 2013, 96, 170-183. [CrossRef]

18. Aboulwafa, M.M.; Youssef, F.S.; Gad, H.A.; Sarker, S.D.; Nahar, L.; Al-Azizi, M.M.; Ashour, M.L. Authentication and discrimination of green tea samples using UV-Visible, FTIR and HPLC techniques coupled with chemometrics analysis. J. Pharm. Biomed. Anal. 2018, 164, 653-658. [CrossRef] [PubMed]

19. Zengin, G. A study on in vitro enzyme inhibitory properties of Asphodeline anatolica: New sources of natural inhibitors for public health problems. Ind. Crops Prod. 2016, 83, 39-43. [CrossRef]

20. Janibekov, A.A.; Youssef, F.S.; Ashour, M.L.; Mamadalieva, N.Z. New flavonoid glycosides from two Astragalus species (Fabaceae) and validation of their antihyperglycaemic activity using molecular modelling and in vitro studies. Ind. Crops Prod. 2018, 118, 142-148. [CrossRef]

21. Pujirahayu, N.; Bhattacharjya, D.K.; Suzuki, T.; Katayama, T. $\alpha$-Glucosidase inhibitory activity of cycloartane-type triterpenes isolated from Indonesian stingless bee propolis and their structure-activity Relationship. Pharmaceuticals 2019, 12, 102. [CrossRef] [PubMed]

22. Denizli, N.; Horo, I.; Gülcemal, D.; Masullo, M.; Festa, M.; Capasso, A.; Koz, Ö.; Piacente, S.; Alankuş-Çalışkan, Ö. Cycloartane glycosides from Astragalus plumosus var. krugianus and evaluation of their antioxidant potential. Fitoterapia 2014, 92, $211-218$.

23. Jamila, N.; Khan, N.; Khan, I.; Khan, A.A.; Khan, S.N. A bioactive cycloartane triterpene from Garcinia hombroniana. Nat. Prod. Res. 2016, 30, 1388-1397. [CrossRef] [PubMed]

24. Khan, M.T.H.; Choudhary, M.I.; Mamedova, R.P.; Agzamova, M.A.; Sultankhodzhaev, M.N.; Isaev, M.I. Tyrosinase inhibition studies of cycloartane and cucurbitane glycosides and their structure-activity relationships. Bioorg. Med. Chem. 2006, 14, 6085-6088. [CrossRef]

25. Khan, M.T.H.; Khan, S.B.; Ather, A. Tyrosinase inhibitory cycloartane type triterpenoids from the methanol extract of the whole plant of Amberboa ramosa Jafri and their structure-activity relationship. Bioorg. Med. Chem. 2006, 14, 938-943. [CrossRef]

26. Zengin, G.; Rodrigues, M.J.; Abdallah, H.H.; Custodio, L.; Stefanucci, A.; Aumeeruddy, M.Z.; Mollica, A.; Rengasamy, K.R.; Mahomoodally, M.F. Combination of phenolic profiles, pharmacological properties and in silico studies to provide new insights on Silene salsuginea from Turkey. Comput. Biol. Chem. 2018, 77, 178-186. [CrossRef]

27. Uysal, S.; Aktumsek, A.; Picot, C.M.; Sahan, A.; Mollica, A.; Zengin, G.; Mahomoodally, M.F. A comparative in vitro and in silico study of the biological potential and chemical fingerprints of Dorcycinum pentapyllum subsp. haussknechtii using three extraction procedures. New J. Chem. 2017, 41, 13952-13960.

28. Zengin, G.; Uysal, S.; Ceylan, R.; Aktumsek, A. Phenolic constituent, antioxidative and tyrosinase inhibitory activity of Ornithogalum narbonense L. from Turkey: A phytochemical study. Ind. Crops Prod. 2015, 70, 1-6. [CrossRef]

29. Ślusarczyk, S.; Hajnos, M.; Skalicka-Woźniak, K.; Matkowski, A. Antioxidant activity of polyphenols from Lycopus lucidus Turcz. Food Chem. 2009, 113, 134-138. [CrossRef] 
30. Sobeh, M.; Mamadalieva, N.Z.; Mohamed, T.; Krstin, S.; Youssef, F.S.; Ashour, M.L.; Azimova, S.S.; Wink, M. Chemical profiling of Phlomis thapsoides (Lamiaceae) and in vitro testing of its biological activities. Med.Chem. Res. 2016, 25, 2304-2315. [CrossRef]

31. Re, R.; Pellegrini, N.; Proteggente, A.; Pannala, A.; Yang, M.; Rice-Evans, C. Antioxidant activity applying an improved ABTS radical cation decolorization assay. Free. Rad. Bio. Med. 1999, 26, 1231-1237. [CrossRef]

32. Zengin, G.; Sarikurkcu, C.; Aktumsek, A.; Ceylan, R.; Ceylan, O. A comprehensive study on phytochemical characterization of Haplophyllum myrtifolium Boiss. endemic to Turkey and its inhibitory potential against key enzymes involved in Alzheimer, skin diseases and type II diabetes. Ind.Crops Prod. 2014, 53, 244-251. [CrossRef]

33. Aktumsek, A.; Zengin, G.; Guler, G.O.; Cakmak, Y.S.; Duran, A. Antioxidant potentials and anticholinesterase activities of methanolic and aqueous extracts of three endemic Centaurea L. species. Food Chem. Toxicol. 2013, 55, 290-296. [CrossRef] [PubMed]

34. Nawaz, S.A.; Ayaz, M.; Brandt, W.; Wessjohann, L.A.; Westermann, B. Cation $-\pi$ and $\pi-\pi$ stacking interactions allow selective inhibition of butyrylcholinesterase by modified quinine and cinchonidine alkaloids. Biochem. Biophys. Res. Com. 2011, 404, 935-940. [CrossRef]

35. Lazarova, I.; Zengin, G.; Bender, O.; Zheleva-Dimitrova, D.; Uysal, S.; Ceylan, R.; Gevrenova, R.; Aktumsek, A.; Acar, M.; Gunduz, M. A comparative study of Bulgarian and Turkish Asphodeline lutea root extracts: HPLC-UV profiles, enzyme inhibitory potentials and anti-proliferative activities against MCF-7 and MCF-10A cell lines. J. Fun. Food. 2015, 15, 254-263. [CrossRef]

36. Ismaya, W.T.; Rozeboom, H.J.; Weijn, A.; Mes, J.J.; Fusetti, F.; Wichers, H.J.; Dijkstra, B.W. Crystal structure of Agaricus bisporus mushroom tyrosinase: Identity of the tetramer subunits and interaction with tropolone. Biochemistry 2011, 50, 5477-5486. [CrossRef]

37. Mollica, A.; Zengin, G.; Durdagi, S.; Ekhteiari Salmas, R.; Macedonio, G.; Stefanucci, A.; Dimmito, M.P.; Novellino, E. Combinatorial peptide library screening for discovery of diverse $\alpha$-glucosidase inhibitors using molecular dynamics simulations and binary QSAR models. J. Biomol. Str. Dynam. 2019, 37, 726-740. [CrossRef]

38. Halgren, T.A.; Murphy, R.B.; Friesner, R.A.; Beard, H.S.; Frye, L.L.; Pollard, W.T.; Banks, J.L. Glide: A new approach for rapid, accurate docking and scoring. 2. Enrichment factors in database screening. J. Med. Chem. 2004, 47, 1750-1759.

39. Halgren, T.A. Identifying and characterizing binding sites and assessing druggability. J. Chem. Inform. Model. 2009, 49, 377-389. [CrossRef] 